\title{
Small Molecule Cardiogenol C Upregulates Cardiac Markers and Induces Cardiac Functional Properties in Lineage- Committed Progenitor Cells
}

\author{
Agnes K. Mike ${ }^{a}$ Xaver Koenig ${ }^{a}$ Moumita Koley ${ }^{b}$ Philipp Heher ${ }^{c}$ Gerald Wahla \\ Lena Rubia Michael Schnürch ${ }^{b}$ Marko D. Mihovilovic ${ }^{b}$ Georg Weitzer ${ }^{c}$ \\ Karlheinz Hilbera \\ ${ }^{a}$ Center for Physiology and Pharmacology, Department of Neurophysiology and -Pharmacology, \\ Medical University of Vienna, 'Institute of Applied Synthetic Chemistry, Vienna University of \\ Technology, 'Max F. Perutz Laboratories, Department of Medical Biochemistry, Medical University of \\ Vienna, Vienna, Austria
}

\section{Key Words}

Cardiac cell therapy $\cdot$ Cardiac functional properties - Cardiogenol $C \cdot$ Cardiomyogenic small molecule $\cdot$ Lineage-committed progenitor cells

\begin{abstract}
Background/Aims: Cell transplantation into the heart is a new therapy after myocardial infarction. Its success, however, is impeded by poor donor cell survival and by limited transdifferentiation of the transplanted cells into functional cardiomyocytes. A promising strategy to overcome these problems is the induction of cardiomyogenic properties in donor cells by small molecules. Methods: Here we studied cardiomyogenic effects of the small molecule compound cardiogenol $\mathrm{C}(\mathrm{CgC})$, and structural derivatives thereof, on lineage-committed progenitor cells by various molecular biological, biochemical, and functional assays. Results: Treatment with $\mathrm{CgC}$ up-regulated cardiac marker expression in skeletal myoblasts. Importantly, the compound also induced cardiac functional properties: first, cardiac-like sodium currents in skeletal myoblasts, and secondly, spontaneous contractions in cardiovascular progenitor cell-derived cardiac bodies. Conclusion: $\mathrm{CgC}$ induces cardiomyogenic function in lineagecommitted progenitor cells, and can thus be considered a promising tool to improve cardiac repair by cell therapy.
\end{abstract}




\section{Introduction}

The adult human heart cannot effectively regenerate after injury. Therefore, new therapeutic strategies to attain cardiac repair are extensively explored. A promising approach to regenerate the injured heart is intra-cardiac transplantation of stem or progenitor cells. Its success, however, is impaired by poor donor cell survival and by the limited capacity of the transplanted cells to differentiate into functional cardiomyocytes in the acceptor organ [1]. A strategy to overcome the named problems would be the induction of cardiomyogenic function in donor cells prior to transplantation (e.g. [2-4]). Besides attempts to drive the differentiation of induced pluripotent stem cells [5] into cardiomyocytes (e.g. [6]), synthetic small molecules were recently identified, which exhibit remarkable cardiomyogenic effects on various types of stem cells. For example, sulfonyl hydrazone type small molecules were reported to induce the expression of cardiac proteins in different embryonic and adult stem cell types [7]. Noteworthy, these authors also found that sulfonyl hydrazone treatment of the donor cells prior to transplantation improved myocardial repair in a rat model. This highlights the significant therapeutic potential of cardiomyogenic small molecules to support myocardial regeneration. Another also conceivable strategy would be the promotion of cardiac repair by the induction of cardiomyogenic differentiation in residual cardiovascular progenitor cells in situ by small molecules [8]. Besides the sulfonyl hydrazones, the "cardiogenols" [9] represent another promising group of cardiomyogenic small molecules. Thus, the most active compound among the cardiogenols, the diaminopyrimidine cardiogenol C ( $\mathrm{CgC}$ ), induced P19 embryonic carcinoma cells and R1 mouse embryonic stem cells to differentiate into spontaneously beating cardiomyocytes [9]. This study suggested that $\mathrm{CgC}$ exerts a cardiomyogenic effect on embryonic stem cells.

The first aim of the present study was to assess whether, besides acting on pluripotent embryonic stem cells, $\mathrm{CgC}$ also exerts cardiomyogenic effects on already lineage-committed progenitor cell types with a limited degree of plasticity. Secondly, for the first time, we tested if this small molecule induces cardiac functional properties in cells in addition to cardiac marker up-regulation. Finally, structural derivatives of $\mathrm{CgC}$ were studied for cardiomyogenic activity. We report that $\mathrm{CgC}$ treatment induces cardiomyogenic function in lineage-committed progenitor cells.

\section{Materials and Methods}

\section{Cells and culture conditions}

P19 mouse embryonic carcinoma cells (American Type Culture Collection, ATCC) were cultured in minimum essential medium (MEM)-alpha (Sigma-Aldrich) containing $4 \mathrm{mM} \mathrm{L-glutamine,} 50 \mathrm{U} / \mathrm{ml}$ penicillin, $50 \mu \mathrm{g} / \mathrm{ml}$ streptomycin, $7.5 \%$ new born calf serum, and $2.5 \%$ fetal bovine serum at $37{ }^{\circ} \mathrm{C}$ in $5 \% \mathrm{CO}_{2}$. At the begin of an experiment (CgC treatment), control and treated cells were transferred to an "induction medium" (MEM-alpha, $5 \%$ fetal bovine serum, $4 \mathrm{mM} \mathrm{L}$-glutamine, $50 \mathrm{U} / \mathrm{ml}$ penicillin, $50 \mu \mathrm{g} / \mathrm{ml}$ streptomycin) as in [9].

C2C12 mouse skeletal myoblasts (ATCC) were cultured in growth medium consisting of Dulbecco's modified Eagle's medium (DMEM, Life Technologies) containing $4.5 \mathrm{~g} / \mathrm{l}$ glucose, $4 \mathrm{mM} \mathrm{L}$-glutamine, $50 \mathrm{U} / \mathrm{ml}$ penicillin, $50 \mu \mathrm{g} / \mathrm{ml}$ streptomycin, and $20 \%$ fetal calf serum. The cells were incubated at $37{ }^{\circ} \mathrm{C}$ and $5 \% \mathrm{CO}_{2^{\prime}}$ and at about $50-70 \%$ cell confluence (before the emersion of any multi-nucleated myotubes) differentiation was induced by serum reduction. Therefore, myoblasts were incubated in differentiation medium which was identical to the growth medium, except that it contained $2 \%$ horse serum instead of $20 \%$ fetal calf serum. $\mathrm{CgC}$ and other small molecule compounds to be tested were always added at the same time as differentiation was induced.

Human primary skeletal myoblasts were isolated from skeletal muscle biopsies of healthy individuals as in [10]. The procedure was approved by the ethic committee of the Medical University of Vienna (L. Weigl; General Hospital, Vienna, Austria). The myoblasts were kept in growth medium consisting of Ham's F-12 medium (PAA laboratories), $15 \%$ fetal calf serum, $10 \mathrm{ng} / \mathrm{ml}$ epidermal growth factor, $200 \mathrm{ng} / \mathrm{ml}$ insulin, $400 \mathrm{ng} / \mathrm{ml}$ dexamethasone, $0.5 \mathrm{mg} / \mathrm{ml}$ fetuin, $0.5 \mathrm{mg} / \mathrm{ml}$ bovine serum albumin, $7 \mathrm{mM}$ glucose, $4 \mathrm{mM}$ 
L-glutamine, 200 units/ml penicillin, $200 \mu \mathrm{g} / \mathrm{ml}$ streptomycin, and $2.5 \mu \mathrm{g} / \mathrm{ml}$ amphotericin B. Differentiation was induced by switching to differentiation medium which contained DMEM supplemented with $5 \%$ horse serum, $4 \mathrm{mM}$ L-glutamine, $100 \mathrm{ng} / \mathrm{ml}$ insulin, and $0.1 \mu \mathrm{g} / \mathrm{ml}$ gentamicin. $\mathrm{CgC}$ was added at the same time as differentiation was initiated.

If not specified otherwise, treatment of cells with $\operatorname{CgC}$ or other small molecule compounds was performed as follows: stock solutions for each substance were prepared in a concentration of $20 \mathrm{mM}$, whereby the compounds were solved in DMSO. DMSO rather than water had to be used as solvent in order to guarantee sufficient solubility of all the compounds to be tested. The small molecule compounds were normally used in an end concentration of $1 \mu \mathrm{M}$. At this concentration, the cells were exposed to an amount of $0.005 \%$ DMSO. To provide comparable conditions, control cells, which did not obtain small molecule treatment, were always exposed to the same amount of DMSO $(0.005 \%)$. A small molecule concentration of $1 \mu \mathrm{M}$ was chosen for the experiments, because this concentration of CgC sufficed to induce significant cardiomyogenic effects in several different assays, whereas at the same time staying far away from concentrations which generate cellular toxicity (see Fig. 5). Small molecule treatment lasted for 7 days, whereby fresh media were supplied twice during this time period. 7 day treatment duration was chosen, first, because C2C12 cells require about a week in differentiation medium in order to display mature electrophysiological properties [11]. Secondly, also in [9] and [12] CgC treatment durations of several days ( 4 days and 1 to 21 days, respectively) were used.

\section{ANF and Nkx2.5 promoter luciferase reporter gene assays}

For the ANF (atrial natriuretic factor) assay, a fragment containing the rat ANF promoter region was amplified and then subcloned into the PGL3-BV luciferase reporter plasmid [9]. The cells were transiently transfected with this plasmid (a kind gift from P.G. Schultz; The Scripps Research Institute, La Jolla, CA, USA), and with the pRL-SV40 Renilla luciferase control reporter vector (Promega). For transfections (always one day before start of small molecule treatment), lipofectamine plusTM Reagent (Invitrogen) was used according to the manufacturer's protocol. The expression of Renilla luciferase was used as an internal control for normalization of experimental variations such as differences in cell densities and transfection efficiencies. After 7 days of compound treatment (or $0.005 \%$ DMSO treatment of control cells), the cells were harvested, and luciferase activity was measured (Wallac 1420 Victor multilabel counter, Perkin Elmer) using Promega's dual-luciferase reporter assay kit according to the manufacturer's protocol. P19 cells treated with $10 \mathrm{nM}$ all-trans retinoic acid for 7 days served as positive control for the assay. In this low concentration, retinoic acid drives cardiomyogenic differentiation in embryonic stem cells [13, 14]. For experiments to further test the cardiomyogenic activity of $\mathrm{CgC}$, a Nkx2.5 promoter luciferase reporter plasmid (NKE24, Promega pGL3b plasmid (E1751) with an insert of the nkx2.5 promoter region) was used. The experimental procedure applied was identical to that described above for the ANF reporter gene assay.

\section{Electrophysiological studies}

Sodium currents were recorded from differentiated spherically shaped $\mathrm{C} 2 \mathrm{C} 12$ cells at room temperature $\left(22 \pm 1.5^{\circ} \mathrm{C}\right)$ using an Axoclamp $200 \mathrm{~B}$ patch-clamp amplifier (Axon Instruments, Union City, CA) as described previously [15]. Recording was begun $5 \mathrm{~min}$ after whole cell access was attained to minimize time-dependent shifts in gating. Pipettes were formed from aluminosilicate glass (AF150-100-10; Science Products, Hofheim, Germany) with a P-97 horizontal puller (Sutter Instruments, Novato, CA), heat-polished on a microforge (MF-830; Narishige, Tokyo, Japan), and had resistances between 1 and $2 \mathrm{M} \Omega$ when filled with the pipette solution (105 mM CsF, $10 \mathrm{mM} \mathrm{NaCl}, 10 \mathrm{mM}$ EGTA, and $10 \mathrm{mM}$ HEPES, pH 7.3). Voltage-clamp protocols and data acquisition were performed with pCLAMP 6.0 software (Axon Instruments) through a 12-bit analog-to-digital/digital-to-analog interface (Digidata 1200; Axon Instruments). Data were low-pass filtered at $2 \mathrm{kHz}(-3 \mathrm{~dB})$ and digitized at $10-20 \mathrm{kHz}$. Decay half time, a measure of fast inactivation kinetics, was obtained by analyzing the time period between the current peak and the time point at which the current had decayed to $50 \%$. Slow inactivation was elicited by $10 \mathrm{~s}$ prepulses to various potentials $(-100 \mathrm{mV}$ to 0 $\mathrm{mV}$ ) from a holding potential of $-120 \mathrm{mV}$. Immediately thereafter, a $20 \mathrm{~ms}$ hyperpolarization period to -140 $\mathrm{mV}$ allowed the channels to recover from fast inactivation, before a $25 \mathrm{~ms}$ test pulse to $-20 \mathrm{mV}$ was applied to test for the fraction of slow inactivated channels. This fraction was determined by dividing the amplitude of the current elicited by the test pulse following a prepulse to $0 \mathrm{mV}$ through the maximum current amplitude, and subsequent subtraction of the obtained value from 1. i.e. a calculated fraction value of 0.7 represents 
$70 \%$ slow inactivated and 30\% slow inactivation-resistant channels. Sodium current density was calculated by dividing the maximum peak inward current amplitude (normally at $-25 \mathrm{mV}$ ) of a cell by its membrane capacitance. To estimate the inhibition of sodium currents by tetrodotoxin (TTX), the TTX- resistant current fraction was detected. Recordings were made in a bathing solution that consisted of $140 \mathrm{mM} \mathrm{NaCl}, 2.5 \mathrm{mM}$ $\mathrm{KCl}, 1 \mathrm{mM} \mathrm{CaCl}, 1 \mathrm{mM} \mathrm{MgCl}$, and $10 \mathrm{mM}$ HEPES, $\mathrm{pH}$ 7.4. Solution changes were performed with the use of a DAD-8-VC superfusion system (ALA Scientific Instruments, Westbury, NY).

\section{Western blotting}

Western blot analyses were performed for detection of $\mathrm{Na}_{\mathrm{v}} 1.5$ sodium channel protein levels in control and CgC-treated C2C12 skeletal myoblasts. The cells were washed two times with ice-cold PBS before being shock-frozen in liquid nitrogen. Whole cell lysates were prepared with $100 \mu \mathrm{l}$ immunprecipitation buffer added to each $6 \mathrm{~cm}$ dish, containing $25 \mathrm{mM}$ Tris- $\mathrm{HCl}$ (pH=7.5), $150 \mathrm{mM} \mathrm{NaCl}, 10 \mathrm{mM}$ EDTA, 0.5\% Nonidet P-40, 0.1\% Triton X-100 supplied with $1 \mathrm{mM}$ PEFA-block, $10 \mu \mathrm{g} / \mathrm{ml}$ Leupeptin, and $2 \mu \mathrm{g} / \mathrm{ml}$ Aprotinin. The cell suspension was transferred to $1.5 \mathrm{ml}$ Eppendorf tubes and incubated on ice for 30 minutes. During incubation time, the cell slurry was vortexed shortly (about 2 seconds) every 15 minutes. Lysates were ultra-sonicated for one minute and centrifuged at $15.000 \mathrm{rpm}$ at $4{ }^{\circ} \mathrm{C}$ for 30 minutes. The supernatant was transferred to a new $1.5 \mathrm{ml}$ tube. Protein concentration was determined for each sample by BioRad Quick Start Bradford Protein Assay, and $30 \mu \mathrm{g}$ of protein from each sample was denaturated at $95^{\circ} \mathrm{C}$ for $5 \mathrm{~min}$, using sample buffer (15 mM Tris ( $\mathrm{pH}=6.8$ ), $3.6 \mathrm{mM}$ Mercaptoethanol, $6.25 \%$ Glycerin, $0.5 \%$ SDS, $0.025 \%$ Bromphenol blue). The probes were resolved by SDS-PAGE using 7\% separating gels and $5 \%$ collecting gels. Thereafter, proteins were transferred onto nitrocellulose membranes, blocked for 1 hour at room temperature with $5 \%$ BSA, and incubated at room temperature for 2 hours with the primary antibody against $\mathrm{Na}_{v} 1.5$ (ASC-005, Alomone) at a dilution of $1: 10000$ solved in $2 \% \mathrm{BSA}$ with $0.1 \% \mathrm{NaN}_{3}$. Thereafter the secondary antibody (anti-rabbit IgG, Cell Signalling Technology, 7074) was applied in a dilution of $1: 20000$ (solved in 2\% BSA) for 1 hour at room temperature. Protein bands were developed by GE Healthcare ECL Plus Western Blotting Detection Reagent following the manufacturer's protocol. The $\alpha$-tubulin (antibody T6074, $1: 10000$, solved in $2 \% \mathrm{BSA}$ with $0.1 \% \mathrm{NaN}_{3}$, Sigma-Aldrich) signal was used as a loading control. The membranes were exposed on GE Healthcare ECL High performance chemiluminescence film, and the data was evaluated with densitometry (ImageJ software, Wayne Rasband National Institute of Health, USA).

\section{Differentiation assays}

For comparison of differentiation in untreated control and CgC-treated skeletal myoblasts, differentiation assays were performed similar as in [16]. Therefore, C2C12 cells were seeded at about 20\% confluence in growth medium onto $3.5 \mathrm{~cm}$ dishes, and after $24 \mathrm{~h}$, they were transferred to differentiation medium without (control) or with different concentrations of $\operatorname{CgC}(0.01-10 \mu \mathrm{M}) . \mathrm{CgC}$ treatment lasted for 7 days. Thereafter, cells were rinsed with PBS, fixed with 3.5\% paraformaldehyde for 15 minutes at room temperature, washed three times (5 minutes each) with PBS, permeabilized with $0.1 \%$ Triton X-100 for 1 - 4 min, and stained with the DNA dye SYBR Green (1:10000 diluted in PBS; S7563, Life Technologies) in order to visualize the nuclei. At 20-fold magnification, using a Zeiss LSM 510 confocal microscope, the cell margins were well visible (for example see Fig. $3 \mathrm{~A}$, right). For each experiment, myotubes and nuclei were counted in five different areas $\left(0.42 \mathrm{~mm}^{2}\right.$ of size) per dish. Cells containing equal to or more than 3 nuclei were considered to represent differentiated myotubes as e.g. in [17].

\section{Cardiac body experiments}

The murine cardiovascular progenitor cell line A5 was originally isolated from newborn mouse hearts [18]. Cells were maintained on mitotically inactivated SNL76/7 fibroblasts and, after removal of the fibroblasts by adsorption, induced to differentiate by aggregation and formation of cardiac bodies (CBs) exactly as described [18]. Cardiomyogenesis was monitored under the light microscope in these CBs for 35 days, and the percentage of CBs with beating cardiomyocytes, and the number of beating clusters of cardiomyocytes per CB was determined. Clusters of beating cardiomyocytes are three-dimensional aggregates of physically connected cardiomyocytes, which contract rhythmically due to proper electromechanical coupling. Their number and size directly correlate with the extent of cardiomyogenic induction [18]. 
Toxicity assays

For detecting a possible cellular toxicity of $\mathrm{CgC}$, a colorimetric MTT (3-(4,5-dimethylthiazol-2-yl)2,5-diphenyltetrazolium bromide) assay was performed. This assay is based on the principle that only in living cells the yellow tetrazole MTT is reduced to purple formazan [19]. C2C12 cells were seeded in growth medium onto a 96 well plate (3000 cells per well), and after 24 hours, they were transferred to differentiation medium without (control) or with different concentrations of $\operatorname{CgC}(0.01-100 \mu \mathrm{M})$. CgC treatment lasted for 7 days. Thereafter, the MTT assay reagent (EZ4U- E122, Biomedica) was added to the cells following the manufacturer's protocol. After the color change had occurred (1 - 3.5 hours), the absorbance was measured (Wallac 1420 Victor multilabel counter, Perkin Elmer). The values obtained at the reference wavelength of $620 \mathrm{~nm}$ were subtracted from the values obtained at $450 \mathrm{~nm}$. Absorbance from a substrate blank in assay medium without cells was subtracted from all other values. The resulting values correlate with the fraction of viable cells. The cytostatic agent vincristine (VC, $10 \mathrm{nM}$ and $10 \mu \mathrm{M}$ ) served as a positive control harming the cells.

\section{Statistics}

If not otherwise specified data are expressed as means \pm SEM. Statistical comparisons were carried out using two-tailed Student's t-tests (paired or unpaired as indicated). For comparison of more than two groups repeated measures ANOVA and Tukey's Post Hoc tests were performed. A p-value $<0.05^{*}$ was considered significant; $\mathrm{p}<0.01^{* *}$, highly significant.

\section{Chemical syntheses}

All compounds could be obtained using well established synthetic methods. CgC was derived as in [9]. The derivatives VUT-MK093, VUT-MK142, VUT-MK296, VUT-MK310, VUT-MK396, and VUTMK431, were synthesized as reported in our previous paper [20]. VUT-MK092 was prepared in analogy to the procedure reported therein (for details see below). VUT-MK152 was synthesized via subsequent nucleophilic substitution reactions on 2,4-dichloropyrimidines. Initially the less reactive nucleophile, i.e. p-methoxyaniline was introduced in position 4. Subsequently, ethanolamine could be introduced in position 2 which required somewhat forced reaction conditions (see below). In VUT-MK465 and VUT-MK397 the aromatic amine was introduced via a Buchwald-Hartwig cross-coupling reaction [21, 22], followed by installing the aliphatic side chain again via a nucleophilic substitution reaction. All experimental procedures and analytical data can be found below.

\section{Synthesis of VUT-MK465}

Step 1: Synthesis of 2-fluoro- $N$-(4-methoxyphenyl)pyridin-4-amine. 2-Fluoro-4-iodopyridine (50 mg, $0.22 \mathrm{mmol}, 1$ equiv), p-anisidine ( $33 \mathrm{mg}, 0.27 \mathrm{mmol}, 1.2$ equiv), $\mathrm{K}_{2} \mathrm{CO}_{3}$ (108 mg, $0.78 \mathrm{mmol}, 3.5$ equiv), $\mathrm{Pd}(\mathrm{OAc})_{2}$ (1 mg, $0.004 \mathrm{mmol}, 2 \mathrm{~mol} \%$ ), and BINAP (6 mg, $0.004 \mathrm{mmol}, 2 \mathrm{~mol} \%$ ) were charged into a microwave vial and dry toluene $(1 \mathrm{~mL})$ was added. The vial was then sealed, evacuated, and flushed with argon. Then the reaction mixture was irradiated at $180^{\circ} \mathrm{C}$ in a CEM Explorer ${ }^{\mathrm{TM}}$ microwave unit for 30 minutes

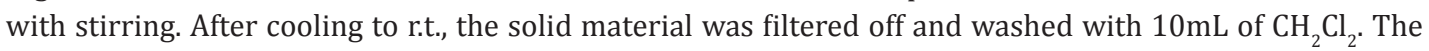
solvent was evaporated and the crude product was purified by column chromatography using PE: EtOAc = 2:1 giving 2-fluoro- $N$-(4-methoxyphenyl)pyridin-4-amine as yellow crystals in $63 \%$ (31 $\mathrm{mg}, 0.14 \mathrm{mmol}$ ) yield. $\mathrm{mp}: 150^{\circ} \mathrm{C}$; TLC: $\mathrm{R}_{\mathrm{f}}=0.32$ (PE:EtOAc = 2:1); GC-MS: $218(\mathrm{M}+, 79), 203$ (100), 155 (13), 219 (11), 175 (10); ${ }^{1} \mathrm{H} \mathrm{NMR}\left(\mathrm{CDCl}_{3}, 200 \mathrm{MHz}\right): \delta=3.83\left(\mathrm{~s}, 3 \mathrm{H},-\mathrm{OCH}_{3}\right), 6.20(\mathrm{~d}, \mathrm{~J}=1.7 \mathrm{~Hz}, 1 \mathrm{H}, \mathrm{H} 5), 6.29-6.35$ (bs, $\left.1 \mathrm{H},-\mathrm{NH}\right)$, $6.51\left(\mathrm{td}, \mathrm{J}_{1}=5.9 \mathrm{~Hz}, \mathrm{~J}_{2}=1.9 \mathrm{~Hz}, 1 \mathrm{H}, \mathrm{H} 3\right), 6.95(\mathrm{~d}, \mathrm{~J}=8.9 \mathrm{~Hz}, 2 \mathrm{H}, \mathrm{H} 3$ '), $7.14(\mathrm{~d}, \mathrm{~J}=8.8 \mathrm{~Hz}, 2 \mathrm{H}, \mathrm{H} 2$ '), 7.81 (d, J =

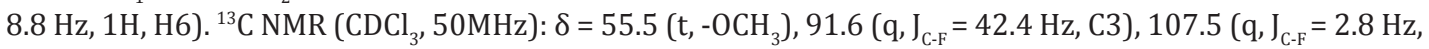
C5), 114.9 (d, C2'), 125.8 (d, C3'), 131.4 (s, C1'), 147.4 (q, J $\left.\mathrm{J}_{\mathrm{C}-\mathrm{F}}=18.7 \mathrm{~Hz}, \mathrm{C} 6\right), 156.5$ (d, J $\left.\mathrm{C}_{\mathrm{C}-\mathrm{F}}=11.6 \mathrm{~Hz}, \mathrm{C} 4\right), 157.6$ (s, C4'), 165.5 (d, $\mathrm{J}_{\mathrm{C}-\mathrm{F}}=232.7 \mathrm{~Hz}, \mathrm{C} 2$ ). Combustion Analysis: Calculated: C 66.05\% H 5.08\% N 12.84\%, Found: C $65.76 \%$ H $4.84 \%$ N $12.62 \%$.

Step 2: Synthesis of 2-[4-(4-methoxyphenylamino)pyridin-2-ylamino]ethanol (VUT-MK465). 2-Fluoro- $N$-(4-methoxyphenyl)pyridin-4-amine (36 mg, $0.16 \mathrm{mmol}$, 1 equiv) was mixed with ethanolamine (80.6 equiv $\mathrm{mg}, 1.32 \mathrm{mmol}, 8$ equiv) and heated in a screw cap vial under argon at $150^{\circ} \mathrm{C}$ in a heating block for 3 days. After cooling to r.t. $2 \mathrm{~N}$ solution of $\mathrm{NaOH}(5 \mathrm{~mL})$ was added and the mixture was extracted with EtOAc (15 mL) for three times. The EtOAc layer was then washed with brine and dried over $\mathrm{Na}_{2} \mathrm{SO}_{4}$. Evaporating the EtOAc layer gave pure VUT-MK465 as beige solid in 89\% yield (38 mg, $0.15 \mathrm{mmol}$ ). $\mathrm{mp}: 164-$ $165^{\circ} \mathrm{C}$; TLC: $\mathrm{R}_{\mathrm{f}}=0.21$ (EtOAc: $\left.\mathrm{MeOH}=10: 1\right) ;{ }^{1} \mathrm{H} \mathrm{NMR}\left(\right.$ DMSO-d $\left._{6}, 200 \mathrm{MHz}\right): \delta=3.22\left(\mathrm{~m}, 2 \mathrm{H}, \mathrm{CH}_{2}\right), 3.45(\mathrm{~m}, 2 \mathrm{H}$, 
$\mathrm{CH}_{2}$ ), $3.72\left(\mathrm{~s}, 3 \mathrm{H}, \mathrm{OCH}_{3}\right.$ ), 5.89 (s, 1H, NH), $6.05(\mathrm{~m}, 2 \mathrm{H}, \mathrm{ArH}, \mathrm{NH}), 6.89$ (d, J= $8.8 \mathrm{~Hz}, 2 \mathrm{H}, \mathrm{H} 2$ ' ), 7.07 (d, J= 8.8 $\left.\mathrm{Hz}, 2 \mathrm{H}, \mathrm{H} 3^{\prime}\right), 7.59$ (d, J= $\left.5.7 \mathrm{~Hz}, 1 \mathrm{H}, \mathrm{H} 3\right), 8.11(\mathrm{~s}, 1 \mathrm{H}, \mathrm{H} 6) ;{ }^{13} \mathrm{C}$ NMR (DMSO-d $\left.{ }_{6}, 50 \mathrm{MHz}\right): \delta=43.8\left(\mathrm{t}, \mathrm{CH}_{2}\right), 55.2$ $\left(\mathrm{q}, \mathrm{OCH}_{3}\right), 60.7\left(\mathrm{t}, \mathrm{CH}_{2}\right.$ ), 89.3 (d, C2'), 100.8 (d, C3'), 114.4 (d, C2), 122.9 (d, C3), 133.9 (s, C1'), 147.4 (d, C6), 151.9 (s, C4'), 154.9 (s, C4), 159.9 (s, C2); HR-MS: Predicted $[\mathrm{MH}]^{+}=260.1394$; Measured [MH] ${ }^{+}=260.1400$. Diff. in $\mathrm{ppm}=2.31$;

\section{Synthesis of VUT-MK397}

Step 1: Synthesis of 6-chloro- $N$-(4-methoxyphenyl)pyridin-2-amine. 2,6-Dichloropyridine (100 $\mathrm{mg}, 0.68 \mathrm{mmol}, 1$ equiv,), p-anisidine ( $100 \mathrm{mg}, 0.81 \mathrm{mmol}, 1.2$ equiv), $\mathrm{K}_{2} \mathrm{CO}_{3}(329 \mathrm{mg}, 2.38 \mathrm{mmol}, 3.5$ equiv), $\mathrm{Pd}(\mathrm{OAc})_{2}(3 \mathrm{mg}, 0.014 \mathrm{mmol}, 2 \mathrm{~mol} \%)$, and BINAP ( $9 \mathrm{mg}, 0.014 \mathrm{mmol}, 2 \mathrm{~mol} \%$ ) were charged into a microwave vial and dry toluene $(2.5 \mathrm{~mL})$ was added. The vial was then sealed, evacuated and flushed with argon. Then the reaction mixture was irradiated at $180^{\circ} \mathrm{C}$ in a CEM Explorer ${ }^{\mathrm{TM}}$ microwave unit for 30 minutes with stirring. After cooling to r.t., the solid material was filtered off and washed with $10 \mathrm{~mL}$ of $\mathrm{CH}_{2} \mathrm{Cl}_{2}$. The solvent was evaporated and the crude product was purified by column chromatography using PE: EtOAc $=4: 3$ to give 6-chloro- $N$-(4-methoxyphenyl)pyridin-2-amine as yellow solid in $72 \%$ yield $(115$ mg, 0.49 mmol). mp: 74-76º ${ }^{\circ}$;LC: $\mathrm{R}_{\mathrm{f}}=0.41$ (PE: $\left.\mathrm{CH}_{2} \mathrm{Cl}_{2}=4: 3\right)$; GC-MS: 219 (100), 234 (M+, 234), 221 (32), 112 (30), 233 (27); ${ }^{1} \mathrm{H}$ NMR ( $\left.\mathrm{CDCl}_{3}, 200 \mathrm{MHz}\right): \delta=3.81\left(\mathrm{~s}, 3 \mathrm{H}, \mathrm{OCH}_{3}\right), 6.52(\mathrm{~d}, \mathrm{~J}=8.2 \mathrm{~Hz}, 1 \mathrm{H}, \mathrm{H} 5), 6.65$ (d, $\mathrm{J}=7.6 \mathrm{~Hz}, 1 \mathrm{H}, \mathrm{H} 3), 6.74(\mathrm{~s}, 1 \mathrm{H}, \mathrm{NH}), 6.89(\mathrm{~d}, \mathrm{~J}=9.4 \mathrm{~Hz}, 2 \mathrm{H}, \mathrm{H} 3$ '), $7.19(\mathrm{~d}, \mathrm{~J}=7.2 \mathrm{~Hz}, 2 \mathrm{H}, \mathrm{H} 2$ '), 7.34 (t, J = 7.9 $\mathrm{Hz}, 1 \mathrm{H}, \mathrm{H} 4) .{ }^{13} \mathrm{C}$ NMR $\left(\mathrm{CDCl}_{3}, 50 \mathrm{MHz}\right): \delta=54.6$ (q, OCH $\left.{ }_{3}\right), 103.8$ (d), 112.4 (d), 113.8 (d), 123.7 (d), 131.1 (s, C1'), 139.1 (d), 148.5 (s, C4'), 155.9 (s, C6), 156.4 (s, C2). Combustion Analysis: Cal. C 61.41\%, H 4.72\%, N $11.94 \%$ : Found C $61.42 \%, \mathrm{H} 4.52 \%$, N $11.78 \%$.

Step 2: Synthesis of 3-[6-(4-methoxyphenylamino)pyridin-2-ylamino]propan-1-ol (VUT-MK397). 6-Chloro- $N$-(4-methoxyphenyl)pyridin-2-amine $(95 \mathrm{mg}, 0.41 \mathrm{mmol}, 1$ equiv) and propanolamine (244 $\mathrm{mg}$, $3.25 \mathrm{mmol}, 8$ equiv) were mixed and heated in a screw cap vial under argon at $150^{\circ} \mathrm{C}$ in a heating block for 3 days. After cooling to r.t. water ( $5 \mathrm{~mL}$ ) was added and the mixture was extracted with EtOAc ( $5 \mathrm{~mL})$ for three times. The EtOAc layer was then washed with brine and then dried over $\mathrm{Na}_{2} \mathrm{SO}_{4}$. Evaporating the EtOAc layer gave the crude product. Pure VUT-MK397 was obtained by flash column chromatography (EtOAc) as colorless oil in $64 \%$ yield $\left(72 \mathrm{mg}, 0.26 \mathrm{mmol}\right.$ ). TLC: $\mathrm{R}_{\mathrm{f}}=0.40$ ( EtOAc ); ${ }^{1} \mathrm{H}$ NMR $\left(\mathrm{CDCl}_{3}, 200 \mathrm{MHz}\right): \delta=1.65-$ $1.83\left(\mathrm{~m}, 2 \mathrm{H}, \mathrm{CH}_{2}\right), 3.29\left(\mathrm{t}, \mathrm{J}=6.3 \mathrm{~Hz}, 2 \mathrm{H}, \mathrm{CH}_{2}\right), 3.64\left(\mathrm{t}, \mathrm{J}=5.8 \mathrm{~Hz}, 2 \mathrm{H}, \mathrm{CH}_{2}\right), 3.71\left(\mathrm{~s}, 3 \mathrm{H}, \mathrm{OCH}_{3}\right), 5.72(\mathrm{~d}, \mathrm{~J}=8.2$ $\mathrm{Hz}, 1 \mathrm{H}, \mathrm{ArH}$ ), 5.83 (d, J = 8.2, 1H, ArH), 8.79 (d, J = 8.9 Hz, 2H, H2' /H3'), 7.09 (d, J = 8.8 Hz, 2H, H2' /H3'), 7.18 (d, J = $8.02 \mathrm{~Hz}, 1 \mathrm{H}, \mathrm{ArH}), 8.34(\mathrm{~s}, 2 \mathrm{H}, \mathrm{NH}) .{ }^{13} \mathrm{C} \mathrm{NMR}\left(\mathrm{CDCl}_{3}, 50 \mathrm{MHz}\right): \delta=31.8\left(\mathrm{t}, \mathrm{CH}_{2}\right), 38.8\left(\mathrm{t}, \mathrm{NCH}_{2}\right), 55.5$ $\left(\mathrm{q}, \mathrm{OCH}_{3}\right), 59.2\left(\mathrm{t}, \mathrm{OCH}_{2}\right), 94.1$ (d), 94.7 (s, C1'), 114.6 (d), 125.3 (d), 131.6 (s, C4'), 142.3 (s, C6), 153.9 (d), $155.2(\mathrm{~s}, \mathrm{C2}), 165.9$ (d). HR-MS: Predicted $[\mathrm{MH}]^{+}=274.1550$; Measured $[\mathrm{MH}]^{+}=274.1555$. Diff in $\mathrm{ppm}=1.82$.

\section{2-[4-(4-Methoxyphenylamino)pyrimidin-2-ylamino]ethanol (VUT-MK152)}

2,4-Dichloropyrimidine (100 mg, $0.67 \mathrm{mmol}$, 1equiv), p-morpholino aniline (132 mg, $0.74 \mathrm{mmol}, 1.1$ equiv) and DIPEA (104.7 mg, $0.81 \mathrm{mmol}, 1.2$ equiv) were dissolved in EtOH ( $4 \mathrm{~mL})$ at $0^{\circ} \mathrm{C}$ under nitrogen atmosphere and refluxed for $5 \mathrm{~h}(4 \mathrm{~mL})$. The crude product was filtered off and washed with cold EtOAc. This crude product (110 mg, $0.38 \mathrm{mmol}$, 1equiv) and ethanol amine ( $46.4 \mathrm{mg}, 0.76 \mathrm{mmol}$, 2eq) were charged into a microwave vial in $\mathrm{n}-\mathrm{BuOH}(5 \mathrm{~mL})$ and heated at $200^{\circ} \mathrm{C}$ for 30 minutes in microwave. After cooling to r.t., solvent (n-BuOH) was evaporated to give the crude product and excess of the amine. Purified product was obtained by crystallization from $\mathrm{EtOH}$ and $\mathrm{n}-\mathrm{BuOH}$ solvent mixture as light yellow solid in $65 \%(110$ mg, $0.35 \mathrm{mmol}$ ) yield. mp: $178-179^{\circ} \mathrm{C}$; TLC: $\mathrm{R}_{\mathrm{f}}=0.13$ (PE: EtOAc= 1:3); ${ }^{1} \mathrm{H}$ NMR $\left(\mathrm{CD}_{3} \mathrm{OD}, 200 \mathrm{MHz}\right): \delta=3.09$ $\left(\mathrm{t}, \mathrm{J}=4.8 \mathrm{~Hz}, 4 \mathrm{H}, 2 \mathrm{NCH}_{2}\right), 3.47\left(\mathrm{t}, \mathrm{J}=5.6 \mathrm{~Hz}, 2 \mathrm{H}, \mathrm{NCH}_{2}\right), 3.70\left(\mathrm{t}, \mathrm{J}=5.6 \mathrm{~Hz}, 2 \mathrm{H}, \mathrm{OCH}_{2}\right), 3.83(\mathrm{t}, \mathrm{J}=4.8 \mathrm{~Hz}, 4 \mathrm{H}$, $\left.2 \mathrm{OCH}_{2}\right), 5.96(\mathrm{~d}, \mathrm{~J}=5.9 \mathrm{~Hz}, 1 \mathrm{H}, \mathrm{H} 5), 6.95$ (d, J = $9.2 \mathrm{~Hz}, 2 \mathrm{H}, \mathrm{H} 2$ '), 7.47 (d, J = $8.9 \mathrm{~Hz}, 2 \mathrm{H}, \mathrm{H} 3$ '), 7.71 (d, J = 5.9 $\mathrm{Hz}, 1 \mathrm{H}, \mathrm{H6}) \cdot{ }^{13} \mathrm{C}$ NMR $\left(\mathrm{CD}_{3} \mathrm{OD}, 50 \mathrm{MHz}\right): \delta=44.8\left(\mathrm{t}, \mathrm{NCH}_{2}\right), 51.2\left(\mathrm{t}\right.$, morpholino- $\left.\mathrm{NCH}_{2}\right), 62.2\left(\mathrm{t}, \mathrm{OCH}_{2}\right), 68.1$ (t, morpholino- $\mathrm{OCH}_{2}$ ), 97.3 (d, C5), 117.6 (d, C3'), 123.6 (d, C2'), 134.1 (s, C1'), 149.1 (s, C4'), 155.9 (d, C6), $163.0(\mathrm{~s}, \mathrm{C} 4), 163.3(\mathrm{~s}, \mathrm{C} 2)$. HR-MS: Predicted $[\mathrm{MH}]^{+}=275.1508$; Measured $[\mathrm{MH}]^{+}=275.1498$. Diff in ppm $=$ 3.6

\section{Synthesis of VUT-MK092}

Step 1: Synthesis of 6-chloro- $N$-(4-methoxyphenyl)pyrimidine-4-amine hydrochloride. 4,6-Dichloropyrimidine ( $1.57 \mathrm{~g}, 10.6 \mathrm{mmol}, 1.3 \mathrm{equiv})$ and $\mathrm{p}$-methoxyaniline $(1 \mathrm{~g}, 8.10 \mathrm{mmol}, 1$ equiv) were dissolved in $i-\mathrm{PrOH}(15 \mathrm{~mL})$ and $\mathrm{HCl}(37 \%, 1.5 \mathrm{~mL})$ was added drop wise under $\mathrm{N}_{2}$ atmosphere. The reaction mixture 
was then refluxed $\left(84^{\circ} \mathrm{C}\right)$ for 2.5 hour under nitrogen atmosphere. The reaction was monitored by TLC and was generally finished after $2.5 \mathrm{~h}$. A precipitate appeared after cooling. The reaction mixture was then kept in the freezer overnight for complete precipitation. The colorless precipitate was filtered and washed with cold $i$-PrOH to get the pure product 6-chloro- $N$-(4-methoxyphenyl)pyrimidine-4-amine hydrochloride as colorless solid in $56 \%$ yield $(1.60 \mathrm{~g}, 5.88 \mathrm{mmol}) . \mathrm{Mp}: 121-123^{\circ} \mathrm{C}$; TLC: $\mathrm{R}_{\mathrm{f}}=0.85$ (EtOAc: $\left.\mathrm{EtOH}=10: 1\right) ;{ }^{1} \mathrm{H} \mathrm{NMR}$ (DMSO-d $\left.{ }_{6}, 200 \mathrm{MHz}\right): \delta=3.75\left(\mathrm{~s}, 3 \mathrm{H}, \mathrm{OCH}_{3}\right.$ ), $6.73(\mathrm{~s}, 1 \mathrm{H}, \mathrm{H} 5), 6.95$ (d, J = $8.8 \mathrm{~Hz}, 2 \mathrm{H}, \mathrm{H} 3$ '), 7.49 (d, J = $8.8 \mathrm{~Hz}$, $2 \mathrm{H}, \mathrm{H} 2$ '), 8.38 (s, 1H, H2), 9.89 (s, 1H, HCl). ${ }^{13} \mathrm{C}$ NMR (DMSO-d $\left.{ }_{6}, 50 \mathrm{MHz}\right): \delta=55.3$ (q, OCH ${ }_{3}$ ), 104.1 (d, C5), 114.1 (d, C3'), 122.6 (d, C2'), 131.6 (s, C1'), 155.7 (s, C4'), 157.1 (s, C6), 158.1 (d, C2), 161.3 (s, C4).

Step 2: Synthesis of 3-[6-(4-methoxyphenylamino)pyrimidine-4-ylamino]propan-1-ol (VUT-MK092).

6-Chloro- $N$-(4-methoxyphenyl)pyrimidine-4-amine hydrochloride $(250 \mathrm{mg}, 0.92 \mathrm{mmol}, 1$ equiv), propanolamine ( $75 \mathrm{mg}, 1.0 \mathrm{mmol}, 1.1$ equiv), and DIPEA (296 mg, $2.29 \mathrm{mmol}, 2.5$ equiv) in $n$-BuOH (5 $\mathrm{mL}$ ) were heated to $200^{\circ} \mathrm{C}$ for 45 minutes in a microwave. The crude product was obtained by evaporating $n$-BuOH. Crystallization from $n$-BuOH-EtOH solvent mixture gave the pure product VUT-MK092 as colorless solid in $85 \%$ yield $(215 \mathrm{mg}, 0.78 \mathrm{mmol}) . \mathrm{Mp}: 151-152^{\circ} \mathrm{C}$; TLC: $\mathrm{R}_{\mathrm{f}}=0.19$ (EtOAc:EtOH=10:1); ${ }^{1} \mathrm{H} \mathrm{NMR}$ (DMSO- $\left.\mathrm{d}_{6}, 200 \mathrm{MHz}\right): \delta=1.57-1.73\left(\mathrm{~m}, 2 \mathrm{H}, \mathrm{CH}_{2}\right), 3.19\left(\mathrm{q}, \mathrm{J}=6.1 \mathrm{~Hz}, 2 \mathrm{H}, \mathrm{NCH}_{2}\right), 3.44\left(\mathrm{q}, \mathrm{J}=5.6 \mathrm{~Hz}, 2 \mathrm{H}, \mathrm{OCH}_{2}\right.$ ), $3.71\left(\mathrm{~s}, 3 \mathrm{H}, \mathrm{OCH}_{3}\right), 4.48(\mathrm{t}, \mathrm{J}=5.2 \mathrm{~Hz}, 1 \mathrm{H}, \mathrm{NH}), 5.62(\mathrm{~s}, 1 \mathrm{H}, \mathrm{H} 5), 6.72(\mathrm{t}, \mathrm{J}=5.4 \mathrm{~Hz}, 1 \mathrm{H}, \mathrm{NH}), 6.86(\mathrm{~d}, \mathrm{~J}=8.8 \mathrm{~Hz}$, $\left.2 \mathrm{H}, \mathrm{H} 3^{\prime}\right), 7.35$ (d, J = $8.8 \mathrm{~Hz}, 2 \mathrm{H}, \mathrm{H2}$ '), 8.11 (s, $\left.1 \mathrm{H}, \mathrm{H} 2\right), 8.69(\mathrm{~s}, 1 \mathrm{H}, \mathrm{OH}) \cdot{ }^{13} \mathrm{C}$ NMR (DMSO-d $\mathrm{f}^{\prime}, 200 \mathrm{MHz}$ ): $\delta=32.6$ $\left(\mathrm{t}, \mathrm{CH}_{2}\right), 37.5\left(\mathrm{t}, \mathrm{CH}_{2}\right), 55.3\left(\mathrm{q}, \mathrm{OCH}_{3}\right), 58.5\left(\mathrm{t}, \mathrm{CH}_{2}\right), 80.1$ (d, C5), 114.1 (s, C1'), 122.0 (d, C3'), 133.4 (d, C2'), 154.5(s, C4'), 157.5 (d, C2), 160.5 (s, C4), 162.7 (s, C6). Combustion Analysis: Cal. C 61.30, H 6.61, N 19.42: Found C 61.17, H 6.67, N 19.39 .

\section{Results}

$\mathrm{CgC}$ up-regulates the expression of the cardiac markers ANF and Nkx2.5

CgC (Fig. 1A) was previously shown to induce the expression of cardiac markers in pluripotent P19 embryonic carcinoma cells [9]. Figure 1B shows that we could reproduce this finding by using a luciferase-based reporter gene assay. Thus, after treatment of P19 cells with $1 \mu \mathrm{M} \operatorname{CgC}$ for 7 days, the expression of atrial natriuretic factor (ANF, $n p p a$ ) was significantly increased compared to untreated control cells. ANF is a commonly used cardiac marker gene. P19 cells treated with $10 \mathrm{nM}$ retinoic acid for 7 days (positive control, five experiments) revealed $3.2 \pm 0.6$ - fold luciferase activities compared with control cells. These experiments confirm the findings of [9], suggesting that $\mathrm{CgC}$ has a "cardiomyogenic effect" on P19 cells. To test if $\mathrm{CgC}$ does not only act cardiomyogenic on pluripotent embryonic stem cells, but also on a progenitor cell type that is already lineage-committed, we performed analogous ANF luciferase assay experiments on C2C12 skeletal myoblasts. This cell type has also previously been used for cardiomyogenic differentiation studies [23-25]. Figure 1C (left) shows that, similar as in P19 cells, CgC treatment ( $1 \mu \mathrm{M}, 7$ days) significantly increased ANF expression in $\mathrm{C} 2 \mathrm{C} 12$ cells. In addition, the expression of $\mathrm{Nkx} 2.5$, another frequently used cardiac marker gene (NKX2-5), was also increased by the small molecule (Fig.1C, right).

Because our CgC-containing media comprised a low concentration of DMSO $(0.005 \%)$, which, in higher concentrations (e.g. 0.5 - 1\%), generates cardiomyogenic effects itself (e.g. $[26,27])$, we performed control experiments. Figure 1D shows that 7 day treatment of C2C12 cells with $0.005 \%$ or $0.05 \%$ DMSO failed to induce ANF expression. $0.5 \%$ DMSO, on the other hand, significantly increased ANF expression. These findings suggest that, in the $\mathrm{CgC}$ treatment studies described above (Figs. 1B and C), the small molecule itself, but not DMSO, was causative for cardiac marker up-regulation.

In Figure $1 \mathrm{E}$ we show that the cardiomyogenic effect of $\mathrm{CgC}$ on $\mathrm{C} 2 \mathrm{C} 12$ cells is concentration-dependent. Thus, both ANF (top) and Nkx2.5 (bottom) expression were induced most by $100 \mu \mathrm{M} \mathrm{CgC}$, the highest small molecule concentration used. Because of the cardiomyogenic effect of high concentrations of DMSO (Fig. 1D), for these experiments, CgC was solved in water instead of DMSO.

Finally, auxiliary experiments suggested that $\operatorname{CgC}$ treatment of human skeletal myoblasts generated a similar increase in ANF expression as in C2C12 cells (Fig. 1F). 
Fig. 1. Cardiogenol C ( $\mathrm{CgC}$ ) upregulates cardiac marker expression in $\mathrm{C} 2 \mathrm{C} 12$ skeletal myoblasts. (A) Chemical structure of the small molecule compound CgC. (B) ANF luciferase reporter gene assay performed with control (CTL) and CgC-treated (1 $\mu \mathrm{M}$, 7 days) P19 cells. Luciferase activity (in relative light units, RLU) from eight experiments is expressed as mean \pm SEM normalized to the control. * indicates a significant difference $\quad(p<0.05)$ from the control (paired Student's ttest). (C) ANF (left) and Nkx2.5 (right) luciferase reporter gene assays performed with control (CTL) and CgC-treated ( $1 \mu \mathrm{M}, 7$ days) C2C12 cells. Number of experiments, 13 and 7 , respectively. * $\mathrm{p}<0.05$, and ** $(\mathrm{p}<0.01) \quad$ indicates a significant difference from the con-
A

Cardiogenol C<smiles>COc1ccc(Nc2nccc(NCCO)n2)cc1</smiles>

C $\quad$ 22C12 cells

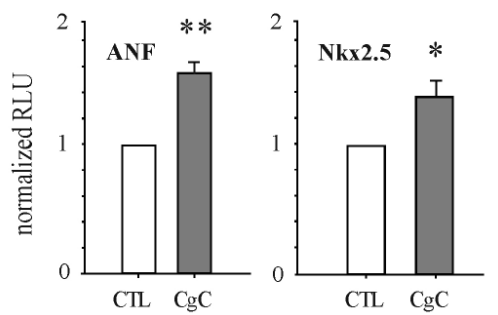

$\mathbf{E}$

C2C12 cells
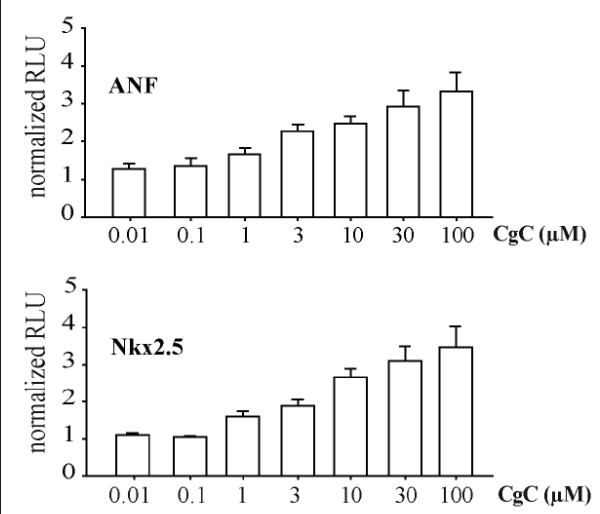

B P19 cells

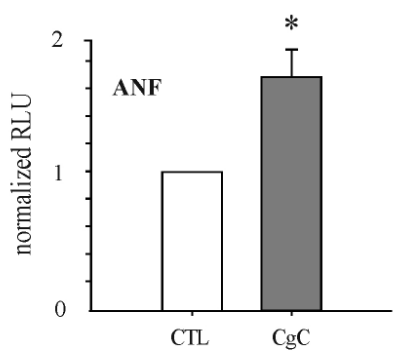

D $\quad \mathrm{C} 2 \mathrm{C} 12$ cells

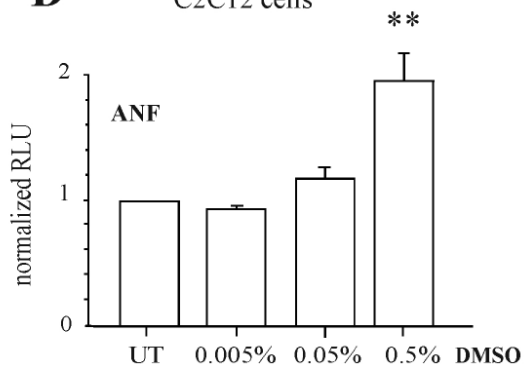

F human skeletal myoblasts

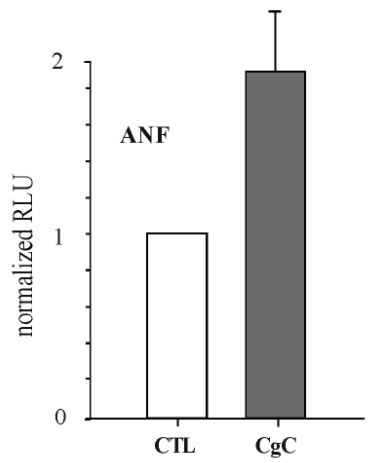

trol (paired Student's t-test). (D) ANF luciferase reporter gene assay performed with untreated (UT) and DMSO-treated (0.005 - 0.5\%, 7 days) C2C12 cells. Luciferase activity (mean \pm SEM) from 4 experiments (each in duplicates) was normalized to the untreated condition. ANOVA performed on the unnormalized raw data revealed a significant difference $(\mathrm{p}<0.01)$ between the 4 tested groups. ${ }^{* *}$ indicates a significant difference $(\mathrm{p}<0.01)$ to the untreated condition (Tukey's post hoc test). (E) ANF (top) and Nkx2.5 (bottom) luciferase reporter gene assays performed on $\mathrm{C} 2 \mathrm{C} 12$ cells treated with different concentrations of $\mathrm{CgC}$. Luciferase activity was normalized to the untreated condition. $\mathrm{n}$ values for the different $\mathrm{CgC}$ concentrations were 3 - 7 for ANF, and each time 4 for Nkx2.5, respectively. For all these experiments water (instead of DMSO) was used as solvent for CgC. (F) ANF luciferase assay performed with control (CTL) and CgC-treated ( $1 \mu \mathrm{M}, 7$ days) human primary skeletal myoblasts. Number of experiments, $5 . \mathrm{p}=0.11$ (paired Student's t-test).

Together these results suggest that CgC exerts cardiomyogenic effects on lineagecommitted skeletal myoblasts. 
Fig. 2. $\mathrm{CgC}$ induces cardiaclike sodium currents in $\mathrm{C} 2 \mathrm{C} 12$ skeletal myoblasts. (A) Original traces of sodium currents in control C2C12 cells after 7 days in differentiation medium elicited by the pulse protocol shown on top. External application of $1 \mu \mathrm{M}$ TTX reversibly reduced the current amplitudes. (B) Superimposed typical examples of current decay following activation by a voltage step from -120 to $-30 \mathrm{mV}$ of a control (empty circle) and $\mathrm{CgC}$-treated cell (filled triangle) on an expanded time scale (left figure part). The intersections of the dashed line with the respective current traces indicate the time points at which the decay half times were determined. On the right, decay half times (means \pm SEM), which represent the time period between the current peak and the time point at which the current had decayed to $50 \%$, were plotted for control (CTL, $\mathrm{n}=16)$ and $\mathrm{CgC}$-treated (1 $\mu \mathrm{M}, 7$ days) $(\mathrm{n}=12)$ cells. ** indicates a significant difference $(\mathrm{p}<0.01)$ from the control (unpaired Student's t-test). (C)
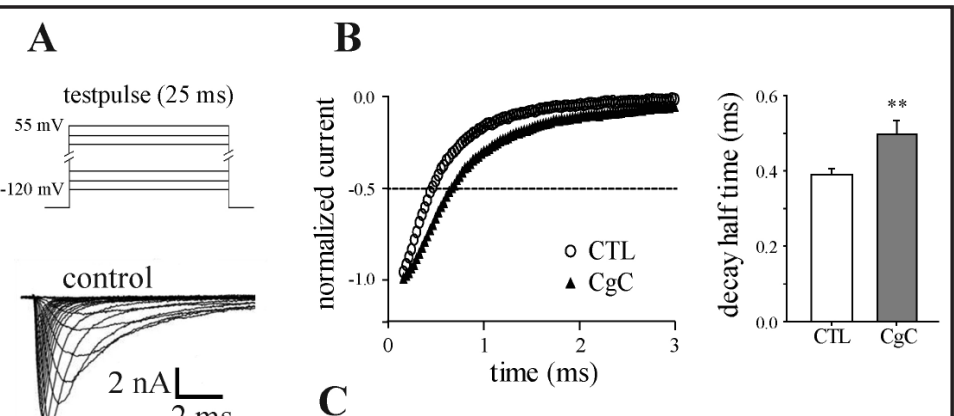

C
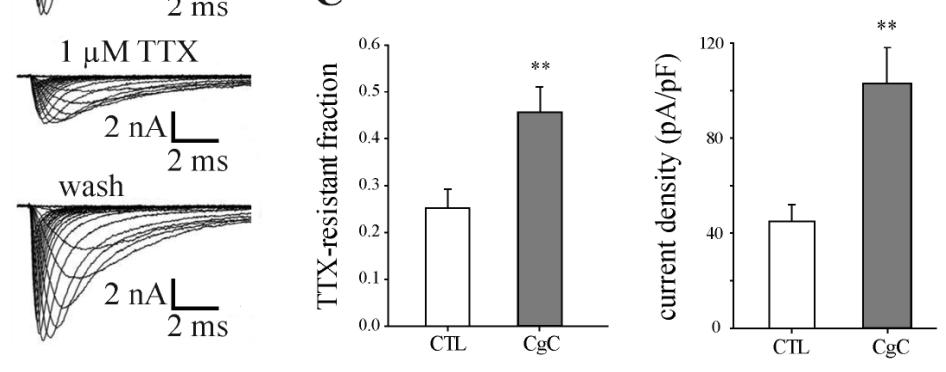

D
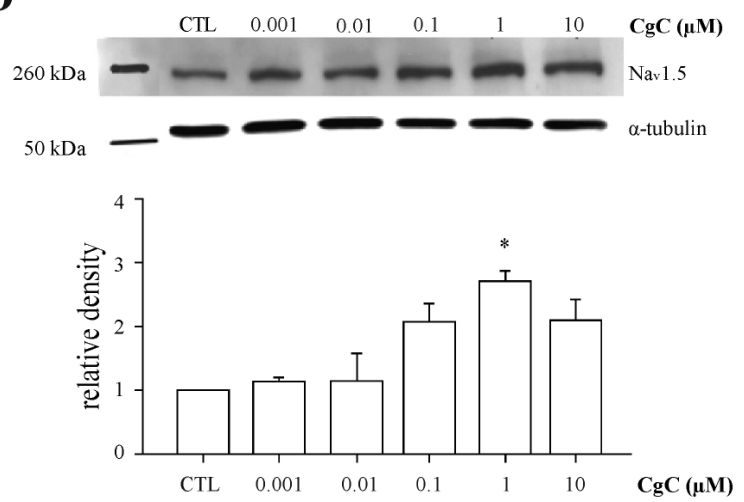

Comparison of TTX-resistant sodium current fractions (left) and sodium current densities (right) in control $(\mathrm{n}=16)$ and CgC-treated $(\mathrm{n}=12)$ C2C12 cells. The TTX-resistant current fraction represents the relative residual current amplitude after equilibrium was reached following external application of $1 \mu \mathrm{M}$ of TTX. ** ( $p<0.01$, unpaired Student's t-test). (D) Shown on top is a typical western blot experiment to compare cardiac $\mathrm{Na}_{v} 1.5$ sodium channel protein levels between control C2C12 cells, and C2C12 cells which were treated with different concentrations of $\mathrm{CgC}$. $\alpha$-tubulin was used as a loading control. In the lower figure part, a results summary, obtained by densitometric analyses of seven such experiments (means \pm SEM) (originating from 3 independent cell preparations and $\mathrm{CgC}$ treatment experiments), is displayed. ANOVA revealed a significant difference $(\mathrm{p}<0.01)$ between the tested groups. ${ }^{*}$ indicates a significant difference $(\mathrm{p}<0.05)$ to the control (Tukey's post hoc test).

\section{$\mathrm{CgC}$ induces cardiac sodium currents in C2C12 skeletal myoblasts}

As an attempt to test if, in addition to cardiac marker up-regulation, $\mathrm{CgC}$ treatment also induces cardiac functional properties in lineage-committed cells, we compared voltagegated sodium currents in control and $\mathrm{CgC}$-treated $\mathrm{C} 2 \mathrm{C} 12$ skeletal myoblasts. We chose to study sodium currents for the following reason: they exhibit distinct and well defined functional differences between skeletal and cardiac myocytes: first, sodium current fast inactivation kinetics is considerably slower in cardiomyocytes (e.g. [28]), and their sodium currents are more resistant to slow inactivation when compared to skeletal myocyte currents [29]. Secondly, the main cardiac sodium channel isoform $\mathrm{Na}_{\mathrm{v}} 1.5$ is resistant to block 


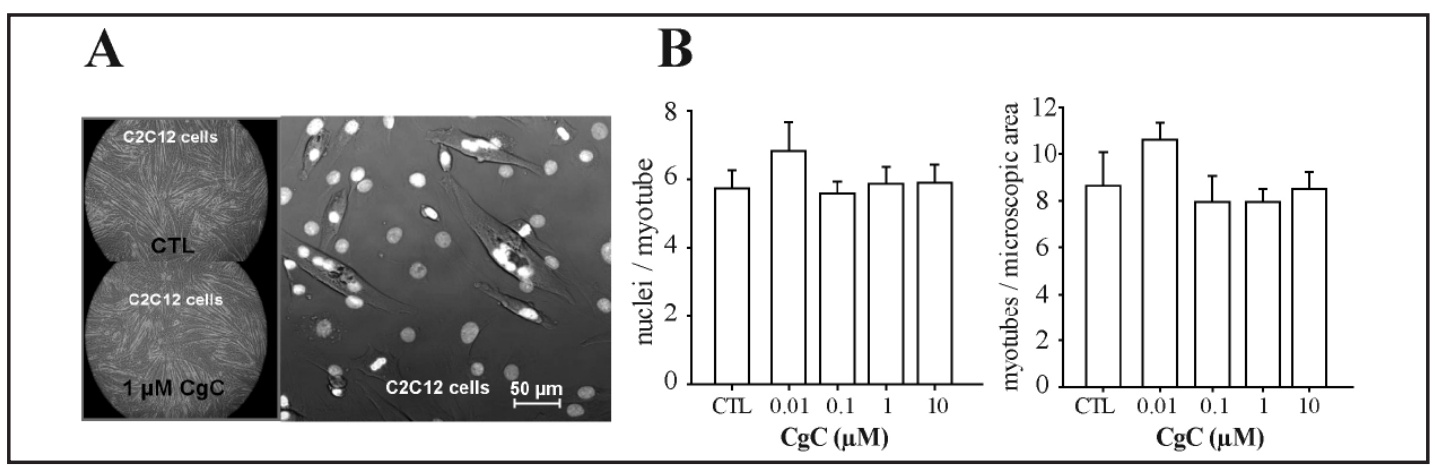

Fig. 3. $\mathrm{CgC}$ does not influence differentiation of $\mathrm{C} 2 \mathrm{C} 12$ skeletal myoblasts. (A) Microscopic images for comparison of the morphology of control (CTL) and CgC-treated C2C12 cells after 7 days in differentiation medium (left). On the right, differentiated control C2C12 cells at reduced cell density, treated with SYBR Green to visualize the nuclei, are displayed. Such images were used to count myotubes and nuclei for analyses of differentiation in control and CgC-treated cells. (B) The numbers of nuclei per myotube (left), and the numbers of myotubes per microscopic area (right) is compared between control C2C12 cells, and C2C12 cells which were treated with different concentrations of CgC. Three independent experiments were performed, and five different areas were considered per dish. Data represent means \pm SEM.

by tetrodotoxin (TTX), whereas skeletal muscle $\mathrm{Na}_{\mathrm{v}} 1.4$ channels are TTX-sensitive (e.g. [30]). Thus, from sodium currents, arising adaptations of their functional properties toward more cardiac-like ones can easily be judged. Figure $2 \mathrm{~B}$ shows that $\mathrm{CgC}$ treatment $(1 \mu \mathrm{M}$, 7 days) significantly delayed the sodium current decay after channel activation in C2C12 cells. This suggests that this small molecule slows the sodium channel inactivation kinetics. In addition, CgC-treated cells showed a higher resistance towards slow inactivation than control cells. Thus, the fractions of slow inactivated channels (see Materials and Methods) amounted to $0.56 \pm 0.04(\mathrm{n}=7)$ in CgC-treated, and $0.70 \pm 0.05(\mathrm{n}=5)$ in control cells $(\mathrm{p}<0.05$; unpaired Student's t-test). The most straight forward explanation for these findings is that $\mathrm{CgC}$ treatment induces the expression of cardiac $\mathrm{Na}_{\mathrm{v}} 1.5$ channels in $\mathrm{C} 2 \mathrm{C} 12$ cells. This was tested first by external application of $1 \mu \mathrm{M}$ TTX (see Fig. 2A), a concentration at which the toxin should almost completely eliminate skeletal muscle $\mathrm{Na}_{\mathrm{v}} 1.4$ channel currents, whereas only block about $50 \%$ of (TTX-resistant) cardiac $\mathrm{Na}_{\mathrm{v}} 1.5$ currents [30]. Indeed we found that, in $\mathrm{CgC}$ - treated $\mathrm{C} 2 \mathrm{C} 12$ cells, the TTX-resistance of the sodium currents was significantly increased (Fig. 2C, left) compared to that of control cells. In addition, the sodium current density, a measure for the number of functional channels in the cell membrane, was markedly increased by $\mathrm{CgC}$ treatment (Fig. 2C, right). Together, these findings strongly suggest that $\mathrm{CgC}$ induces an up-regulation of the expression of the cardiac sodium channel isoform $\mathrm{Na}_{\mathrm{v}} 1.5$ versus the skeletal muscle isoform $\mathrm{Na}_{\mathrm{v}} 1.4$. To further confirm this hypothesis, western blot experiments were performed using a selective anti- $\mathrm{Na}_{\mathrm{v}} 1.5$ sodium channel antibody. Figure $2 \mathrm{D}$ shows that $\mathrm{CgC}$ treatment $\left(1 \mu \mathrm{M}, 7\right.$ days) enhanced $\mathrm{Na}_{\mathrm{v}} 1.5$ protein levels in $\mathrm{C} 2 \mathrm{C} 12$ cells. Thus, as suggested by the electrophysiological experiments described above, $\mathrm{CgC}$ upregulates the expression of the cardiac sodium channel isoform $\mathrm{Na}_{\mathrm{v}} 1.5$. Here it has to be mentioned that, besides $\mathrm{Na}_{\mathrm{v}} 1.5$, cardiomyocytes do also express skeletal muscle $\mathrm{Na}_{\mathrm{v}} 1.4$ and several other TTX-sensitive sodium channel isoforms (reviewed in [31]). These, however, are less abundantly expressed than $\mathrm{Na}_{\mathrm{v}} 1.5$, and therefore not considered in the present study.

Because it is well known that immature (in contrast to adult) skeletal myocytes share several properties with adult cardiomyocytes (e.g. the expression of cardiac protein isoforms such as cardiac myosin alkali light chains [32], cardiac troponin $\mathrm{T}$ [33], and the $\mathrm{Na}_{\mathrm{v}} 1.5$ sodium channel [34]) before they finally reach a mature differentiation state, we tested the effects of $\mathrm{CgC}$ on the differentiation of $\mathrm{C} 2 \mathrm{C} 12$ cells. Thereby we wanted to exclude the possibility that $\mathrm{CgC}$ induces cardiac marker up-regulation and cardiac-like sodium currents simply by the inhibition of differentiation in these cells. Figure $3 \mathrm{~A}$ (left) shows that the morphology of 


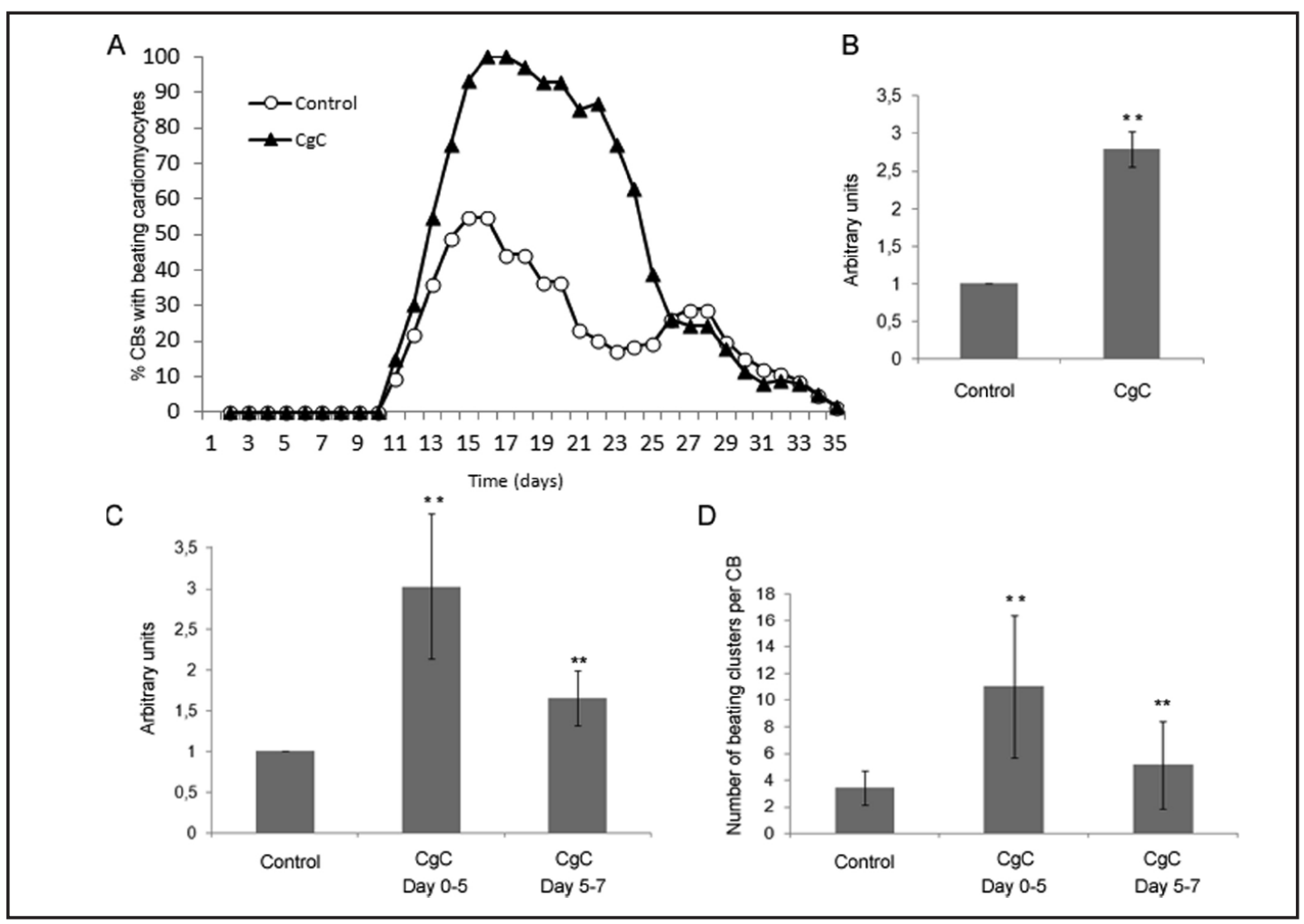

Fig. 4. Influence of $\mathrm{CgC}$ on cardiomyogenesis in cardiovascular progenitor cells. (A) In vitro development of cardiomyocytes from A5 cardiovascular progenitor cells aggregated to form cardiac bodies (CBs) in the absence (Control, empty circles) and presence of $1 \mu \mathrm{M} \mathrm{CgC} \mathrm{between} \mathrm{day} 0$ and 13 (filled triangles). Number of experiments, 4 . Data shown (\% CBs with beating cardiomyocytes) are means of the values of a given day \pm 1 day to get rid of the oscillation caused by the feeding protocol. Number of CBs monitored each, 80. All p values for data points between days 15 to $25<0.01$ (unpaired Student's t-test). (B) Extent of cardiomyogenesis expressed in arbitrary units normalized to the control. Data were derived from the experiments shown in A by calculating the fold increase over control for each day between days 14 to 24 . The bar indicates the mean value \pm standard deviation (STD) ( $p<0.01$, unpaired Student's t-test). (C) Cardiomyogenesis in CBs when CgC was added either between days 0 and 5, or between days 5 and 7. Data (means \pm STD) were sampled between days 12 and 20. Number of experiments, 4 . $(\mathrm{p}<0.01$, unpaired Student's t-test). (D) Mean number of beating cardiomyocyte clusters per CB. Data (means \pm STD) were sampled between days 14 and 17. Number of experiments, 2 ( $\mathrm{p}<0.01$, unpaired Student's t-test).

control C2C12 cells after 7 days in differentiation medium was similar to that of CgC-treated cells. Moreover, both the numbers of nuclei per myotube (Fig. 3B, left), and the numbers of myotubes per microscopic area (Fig. 3B, right) - used as indicators for the differentiation state of the cells- were unaltered by $\mathrm{CgC}$ treatment. Together these experiments suggest that $\mathrm{CgC}$ does not inhibit $\mathrm{C} 2 \mathrm{C} 12$ cell differentiation. Thus, cardiac marker up-regulation, and the induction of cardiac-like sodium currents in C2C12 skeletal myoblasts by this small molecule (see above) seem to be independent of inhibitory effects on differentiation.

$\mathrm{CgC}$ promotes the development of beating cardiomyocytes in cardiovascular progenitor cell-derived cardiac bodies

In order to further characterize the potential of $\mathrm{CgC}$ to induce cardiomyogenic properties in lineage-committed progenitor cells, we switched to another cell type and approach. Thus, we studied if the small molecule increases the differentiation of murine A5 cardiovascular progenitor cells (CVPCs) to rhythmically contracting adult-like cardiomyocytes. A5 CVPCs, restricted to the cardiomyogenic lineage [18], were therefore aggregated, and cardiomyogenesis was monitored in cardiac bodies (CBs) for 35 days (Fig. 4). Addition of 


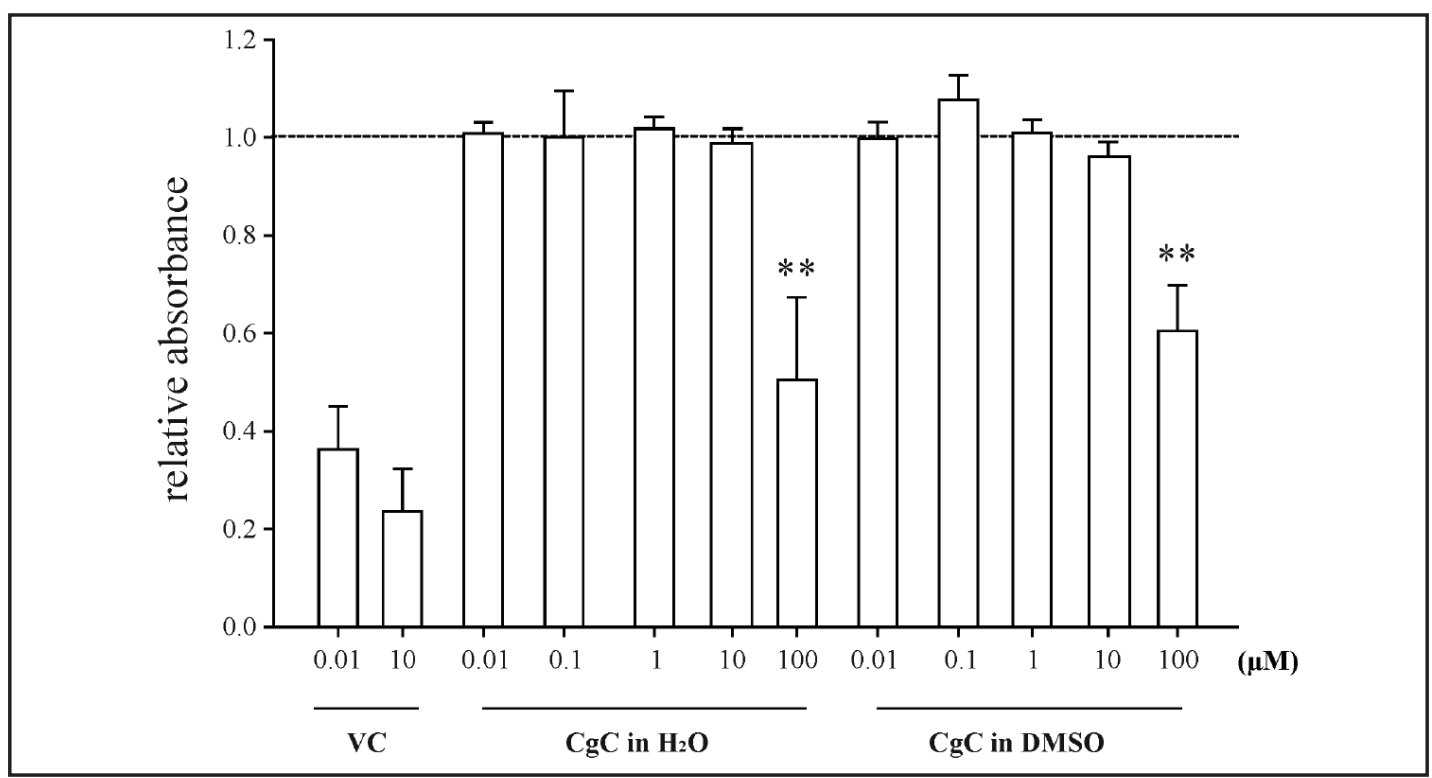

Fig. 5. CgC concentrations up to $10 \mu \mathrm{M}$ do not exert toxic effects on C2C12 cells. MTT toxicity assays were performed on control and CgC-treated cells. $\mathrm{CgC}$ was either dissolved in water (left) or DMSO (right). Absorbance values (means \pm SEM) were normalized to those of untreated cells (dashed line). Three independent experiments were performed, each of which in triplicates. The cytostatic agent vincristine (VC) served as a positive control. Independent of the $\mathrm{CgC}$ solvent $\left(\mathrm{H}_{2} \mathrm{O}\right.$, DMSO) used, ANOVA performed on the unnormalized raw data revealed a significant difference $(\mathrm{p}<0.01)$ between the tested groups. ${ }^{* *}$ indicates a significant difference $(\mathrm{p}<0.01)$ to the respective untreated condition (Tukey's post hoc test).

$1 \mu \mathrm{M} \operatorname{CgC}$ from day 0 on significantly increased myocardial differentiation (Fig. 4A and B) and resulted in a significantly increased percentage of CBs with beating cardiomyocytes (Fig. 4B). Addition of $\mathrm{CgC}$ starting from the very beginning of cardiomyogenesis had a more pronounced effect than adding $\mathrm{CgC}$ only between days 5 and 7 (Fig. 4C). In addition, the number of beating cardiomyocyte clusters was also increased especially when $\mathrm{CgC}$ was added from the very beginning of cardiomyogenesis (Fig. 4D). This suggests that, besides exerting cardiomyogenic effects on $\mathrm{C} 2 \mathrm{C} 12$ skeletal myoblasts, $\mathrm{CgC}$ also promotes the differentiation of CVPCs to contracting cardiomyocytes in a developmental stage-dependent manner. $\mathrm{CgC}$ seems to affect very early differentiation of CVPCs at a developmental stage long before any functional cardiomyocytes are formed on days 11 and later.

\section{CgC concentrations up to $10 \mu \mathrm{M}$ do not exert toxic effects on C2C12 cells}

[9] reported that $\mathrm{CgC}$ showed significant toxicity on embryonic stem cells only at concentrations greater than $25 \mu \mathrm{M}$. Here we tested possible toxic effects of this small molecule on C2C12 cells by using MTT assays. Figure 5 shows that $\mathrm{CgC}$ concentrations up to $10 \mu \mathrm{M}$ (7 day treatment) did not harm the cells. Only at the highest small molecule concentration used, $100 \mu \mathrm{M}$, significant cellular toxicity was observed. CgC either solved in water or DMSO generated a similar effect. We are aware that the use of MTT assays to determine the toxicity of a substance is limited by the fact that neither cellular function nor morphology is tested. This represents a limitation of the performed toxicity tests.

\section{Structure variation of $\mathrm{CgC}$ leads to changes in cardiomyogenic activity}

In order to determine structural characteristics of the small molecule $\mathrm{CgC}$ (Fig. 1A) necessary for its cardiomyogenic activity, several derivatives of CgC (Fig. 6) were synthesized. Thereafter, their cardiomyogenic activity was tested in ANF-luciferase reporter gene assays on $\mathrm{C} 2 \mathrm{C} 12$ cells, the results of which are summarized in Table 1 . It should be emphasized that the current investigation does not represent a comprehensive structure-activity relationship 
Table 1. ANF-luciferase activity values of small molecule-treated C2C12 cells expressed as fold increase over control. Data represent means \pm SEM with the number of performed experiments (n) given in brackets. $\dagger$ notifies $\mathrm{CgC}$ derivatives which were already included in our previous study [20]

\begin{tabular}{|c|c|c|c|c|c|c|c|c|c|c|c|}
\hline $\begin{array}{l}\text { small } \\
\text { molecule } \\
\text { compound }\end{array}$ & $\mathrm{CgC}$ & $\begin{array}{l}\text { †VUT- } \\
\text { MK093 }\end{array}$ & $\begin{array}{c}\text { VUT- } \\
\text { MK092 }\end{array}$ & $\begin{array}{l}\text { †VUT- } \\
\text { MK142 }\end{array}$ & $\begin{array}{c}\text { VUT- } \\
\text { MK152 }\end{array}$ & $\begin{array}{l}\text { †VUT- } \\
\text { MK296 }\end{array}$ & $\begin{array}{l}\text { †VUT- } \\
\text { MK310 }\end{array}$ & $\begin{array}{l}\text { †VUT- } \\
\text { MK396 }\end{array}$ & $\begin{array}{c}\text { VUT- } \\
\text { MK397 }\end{array}$ & $\begin{array}{l}\text { †VUT- } \\
\text { MK431 }\end{array}$ & $\begin{array}{c}\text { VUT- } \\
\text { MK465 }\end{array}$ \\
\hline $\begin{array}{l}\text { normalized } \\
\text { lucif. } \\
\text { activity }\end{array}$ & $\begin{array}{c}1.6 \pm 0.1 \\
(13)\end{array}$ & $\begin{array}{c}2.0 \pm 0.6 \\
(6)\end{array}$ & $\begin{array}{c}1.2 \pm 0.1 \\
(5)\end{array}$ & $\begin{array}{c}2.3 \pm 0.2 \\
(10)\end{array}$ & $1.2 \pm 0.1$ & $\begin{array}{c}1.6 \pm 0.2 \\
\text { (3) }\end{array}$ & $\begin{array}{c}0.9 \pm 0.1 \\
(3)\end{array}$ & $\begin{array}{c}1.7 \pm 0.1 \\
(7)\end{array}$ & $\begin{array}{c}0.7 \pm 0.1 \\
(3)\end{array}$ & $\begin{array}{c}1.2 \pm 0.1 \\
(4)\end{array}$ & $\begin{array}{c}1.0 \pm 0.03 \\
(3)\end{array}$ \\
\hline
\end{tabular}

Fig. 6. Depiction of the chemical structures of the small molecule compounds derived by structural modifications of $\mathrm{CgC}$. Compounds VUT-MK 093, 142, 296, 310, 396, and 431 were already included in our previous study [20].

study, but rather a first step in this direction by changing key features of the molecule. A complete structure-activity relationship study would have been beyond the scope of this work, but is currently a main focus of follow-up studies within our laboratories, taking advantage of hypotheses based on the above observations when changing key structural features at the lead system.

Within a first generation of modifications, we did not employ any changes at the N-substituents (4-methoxyphenyl and $-\mathrm{CH}_{2} \mathrm{CH}_{2} \mathrm{OH}$ ), and investigated the influence of the position and number of the ring nitrogens. Changing the substitution pattern at pyrimidine from 2,4 to 4,6 led to the $\mathrm{CgC}$ regioisomer VUT-MK093. In this case the activity in the ANF assay (2.0-fold compared

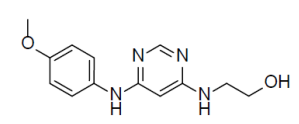

VUT-MK093

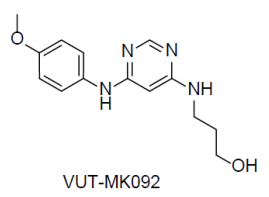

$C_{V U T-M K 142}$
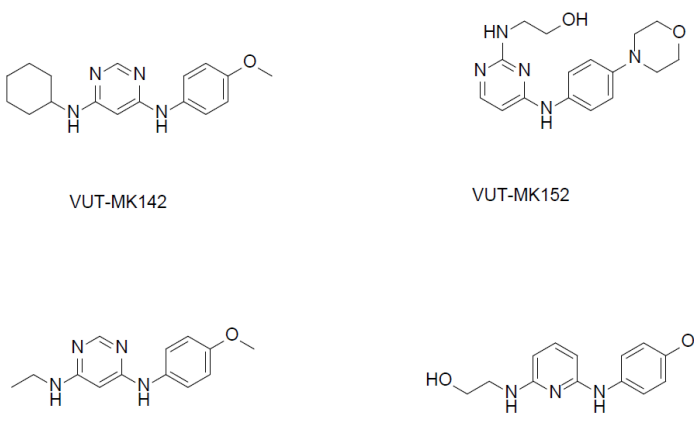

VUT-MK296

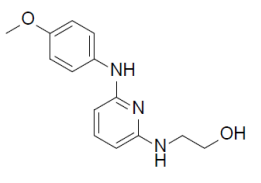

VUT-MK396

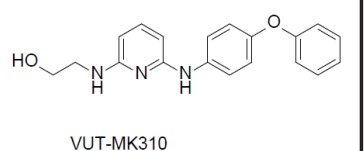

VUT-MK310

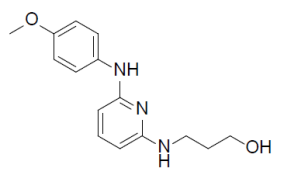

VUT-MK397

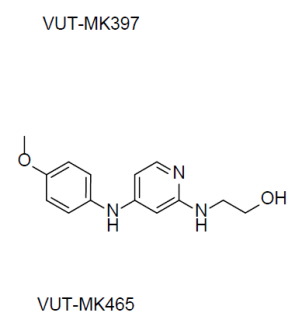

VUT-MK431

to control, see Table 1) was higher compared to $\operatorname{CgC~(1.6).~Subsequently,~we~investigated~the~}$ influence of the ring nitrogens. Eliminating either N1 or N3 led to differently substituted pyridines. Eliminating N1 in $\mathrm{CgC}$ led to its 2,6 disubstiuted pyridine analog VUT-MK396. Interestingly, this compound showed similar activity as $\mathrm{CgC}$ in the ANF assay (1.7). On the other hand if N3 was eliminated, which led to the 2,4-disubstituted pyridine VUT-MK465, the activity was lost completely (1.0). Finally, the influence of N-substituents was investigated. Since 2,4-disubstituted pyrimidines were the topic of a previous report [9] we focused on structural modifications on 4,6-disubstituted pyrimidines and 2,6-disubstituted pyridines. Increasing the chain length of the aliphatic residue by one $\mathrm{CH}_{2}$ group led to a decreased activity as can be seen from the data for VUT-MK397 (pyridine, 0.7) and VUT-MK092 (pyrimidine, 1.2). Also the substituent in para position of the phenyl must not be too large. Switching 
from methoxy to phenoxy as in VUT-MK310 (0.9) led to an inactive compound. Some further derivatives of 4,6-disubstituted pyrimidines were prepared and tested for cardiomyogenic activity. Exchanging ethanolamine in VUT-MK093 for cyclohexylamine as in VUT-MK142 [20] led to the strongest activity in the ANF assay (2.3). Hence, the presence of the hydroxy group does not seem mandatory. This was confirmed by evaluating compound VUT-MK296 (1.6) which gave the same result as $\mathrm{CgC}$ (Table 1). However, a shorter alkyl chain seems to be detrimental for activity since VUT-MK431 was an inactive compound (1.2). Finally, a more severely changed structure was synthesized with VUT-MK152 (Fig. 6). Here, the position of the ethanolamine substituent was changed from 4 to 2 , and additionally a different aniline substituent was introduced in 4-position, which is significantly larger in size. Also this compound proved to be inactive, as VUT-MK152-treated C2C12 cells showed a similar activity in the ANF assay (1.2) as control cells (1.0).

\section{Discussion}

Synthetic small molecules are tools for potential use in regenerative medicine [35, 36]. Among their advantages are efficient delivery into cells, rapid activation or inhibition of targets, the reversibility of their effects, and the potential of modulating multiple molecular targets. These and other features qualify small molecules as promising agents for regenerative medicine developments. A feasible manner to increase the success of intra-cardiac cell transplantation therapy to regenerate the injured heart is the induction of cardiomyogenesis in donor cells prior to transplantation (e.g. [2, 3]). This goal could be achieved by treatment with cardiomyogenic small molecules [7].

Among several small molecules with cardiomyogenic effects [35], the cardiogenols [9], and in particular $\mathrm{CgC}$, have shown promising activity. Thus, $\mathrm{CgC}$ induced embryonic stem cells to differentiate into spontaneously beating cardiomyocytes [9]. Whereas [26] could not confirm cardiomyogenic effects of $\mathrm{CgC}$ on P19 embryonic stem cells, [12] reported that this small molecule drives multipotent mouse hair bulge progenitor cells to transdifferentiate into cardiomyocyte-like cells. In the present study we show that $\operatorname{CgC}$ treatment enhances the expression of the classical cardiac marker ANF in P19 cells. Thereby we confirm the results of [9], suggesting that this small molecule has a cardiomyogenic effect on embryonic stem cells. More importantly, for the first time, here we provide evidence that $\mathrm{CgC}$, besides acting on pluripotent embryonic stem cells, also exerts cardiomyogenic effects on already lineage-committed progenitor cell types such as skeletal myoblasts. This is remarkable because lineage-committed cells, compared to pluripotent embryonic stem cells, only show a limited cardiac differentiation potential, and the molecular signals required to induce cardiomyogenic differentiation in the various cell types may be different $[37,38]$. Together with [9] and [12] our findings suggest that $\operatorname{CgC}$ exerts cardiomyogenic effects on a wide variety of cell types covering pluripotent embryonic and multipotent stem cells, as well as already lineage-committed progenitor cells. We therefore conclude that $\mathrm{CgC}$ is a small molecule with potent cardiomyogenic activity.

A noteworthy difference between CgC's cardiomyogenic effects on embryonic stem cells [9] and C2C12 skeletal myoblasts (present study) lies in the small molecule concentrations needed for activity. Thus, the $\mathrm{EC}_{50}$ value for the $\mathrm{CgC}$ effect on embryonic stem cells was 0.1 $\mu \mathrm{M}$ [9]. This small molecule concentration did not suffice for significant cardiac marker upregulation in $\mathrm{C} 2 \mathrm{C} 12$ cells, but for this cell type considerably higher $\mathrm{CgC}$ concentrations were required (Fig. 1E).

A significant weakness of the majority of published studies describing cardiomyogenic effects of small molecules on stem and/or progenitor cells lies in the circumstance that normally only cardiac marker up-regulation is taken as indicator for cardiomyogenesis. Cardiac marker expression in a cell alone, however, does not prove transdifferentiation into a real cardiomyocyte with specific cardiac-like functional properties. Above all, these attributes comprise appropriate electrical excitability and the ability to contract. In the 
present study we provide first evidence that, besides cardiac marker up-regulation in cells, $\mathrm{CgC}$ also induces cardiac functional properties: first, $\mathrm{CgC}$ treatment induced cardiac-like sodium currents in $\mathrm{C} 2 \mathrm{C} 12$ skeletal myoblasts, and secondly, the small molecule promoted spontaneous contractions in cardiovascular progenitor cell-derived cardiac bodies. The exceptional importance of the induction of cardiomyogenic function in donor cells prior to intra-cardiac transplantation can be exemplarily outlined with reference to $\mathrm{CgC}$ 's promotion of cardiac-like sodium current properties in skeletal myoblasts. A serious side effect observed after skeletal myoblast transplantation into the human heart are cardiac arrhythmias [1]. One conceivable reason therefore are the specific sodium channel properties in skeletal myoblasts, which differ from those in cardiomyocytes, and may disturb proper action potential conduction in the heart. In particular, in the heart, repetitive and long-lasting depolarizations are a normal feature of cardiomyocyte function. Under such conditions, $\mathrm{Na}_{\mathrm{v}} 1.4$ skeletal muscle sodium channels (in contrast to cardiac $\mathrm{Na}_{\mathrm{v}} 1.5$ channels) would undergo almost complete slow inactivation within a short time $[29,39]$. Consequently, the strong likelihood of $\mathrm{Na}_{\mathrm{v}} 1.4$ sodium channels to enter the slow inactivated state, and their long-lasting recovery from this state, would impede repetitive firing of action potentials at a frequency of around $1 \mathrm{~Hz}$ [39], which is a prerequisite for the function of the human heart.

Taken together our data suggest that $\mathrm{CgC}$ induces cardiomyogenic function in addition to cardiac marker up-regulation in treated cells, and support the view that this small molecule is a potent cardiomyogenic agent.

At present very little is known about the molecular targets of $\mathrm{CgC}$. [12] reported that the cardiomyogenic activity of $\mathrm{CgC}$ on mouse hair bulge progenitor cells involves activation of the Wnt signalling pathway and altered expression of several key chromatin remodelling proteins. Our lab has previously shown that the expression of cardiac $\mathrm{Na}_{\mathrm{v}} 1.5$ sodium channels in C2C12 skeletal myoblasts was significantly promoted by moderately rising intracellular calcium levels [15]. Since a similar effect, an up-regulation of $\mathrm{Na}_{\mathrm{v}} 1.5$ channel expression, is also observed in $\mathrm{CgC}$-treated $\mathrm{C} 2 \mathrm{C} 12$ cells (present study), it is tempting to speculate that this small molecule may at least partly act via calcium-dependent signalling mechanisms. As a next step to elucidate CgC's mechanism(s) of action, in the present study we determined essential structural characteristics of the small molecule necessary for cardiomyogenic activity. It seems that the presence of both nitrogens of the pyrimidine ring is beneficial for activity since from the five investigated pyridine derivatives (VUT-MK152, VUT-MK310, VUT-MK396, VUT-MK397, and VUT-MK465) only VUT-MK396 showed activity, whereas four out of seven pyrimidine derivatives were active (CgC, VUT-MK093, VUT-MK142, and VUTMK296). Also the position of the aliphatic and aromatic amine substituent on pyrimidine seems to be important. These positions were inverted in VUT-MK152 placing the aliphatic amine in position 2 and the aromatic amine in position 4, which led to an inactive compound. However, for this compound also the size of the aromatic amine was increased, which can also contribute to the inactivity of this compound. The same is true for the size of the aliphatic amine. It was shown that increasing the chain length from ethanolamine to propanolamine led to a significant drop in activity as in VUT-MK092 and VUT-MK397. The hydroxyl group, on the other hand, seems to be not mandatory since VUT-MK296 showed good activity still. If the aliphatic residue gets too small, activity is lost again as shown for VUT-MK431. Increasing the size of the aromatic amine was detrimental for activity as well (cf. VUT-MK152 and VUTMK310). Overall, these results indicate that not only the 1,3-relationship of the substituents is important, but also their size and the proper location on a pyrimidine scaffold.

We are currently carrying out experiments to identify the molecular targets of $\mathrm{CgC}$.

\section{Conclusions}

Here we report that the small molecule compound $\mathrm{CgC}$ does not only act cardiomyogenic on pluripotent embryonic stem cells [9], but also on already lineage-committed progenitor cell types with a limited degree of plasticity. Moreover, for the first time, we show that this small molecule induces cardiac functional properties in cells in addition to cardiac marker 
up-regulation. Both our main findings suggest that $\operatorname{CgC}$ is a potent cardiomyogenic agent, and as such a promising tool to improve cardiac repair by cell transplantation therapy. In particular, treatment of adult and/or lineage-committed donor cell types with $\operatorname{CgC}$ prior to transplantation may be beneficial. Such cell types are considered safer for clinical use compared with embryonic stem cells, but do normally only show a very limited capacity to integrate into the host organ, and to trans-differentiate into functional cardiomyocytes after transplantation [1]. Treatment of the cells with potent cardiomyogenic agents, such as $\mathrm{CgC}$, may help to overcome these problems, as previously suggested [7]. Another conceivable effect of $\mathrm{CgC}$ is the promotion of cardiac repair by the induction of cardiomyogenic differentiation in residual cardiovascular progenitor cells in situ. Finally, in the present study, we were also able to determine essential structural characteristics of the small molecule compound $\operatorname{CgC}$ necessary for its cardiomyogenic activity.

\section{Acknowledgements}

We would like to thank B. Gundacker for excellent technical assistance, and for keeping the laboratory of G.W. alive. We further thank M. Molin for technical assistance, and L. Weigl for providing the human skeletal myoblasts. P.G. Schultz is acknowledged for providing the plasmid used for the ANF luciferase reporter gene assay. We gratefully acknowledge financial support to this project via AWS (Uni:Invent Project Z090391). The work was also funded by the Austrian Science Fund (P19352 and P23060 to K.H.), and by two grants of the Hochschuljubiläumsstiftung der Stadt Wien (H1249/2009 and H2302/2011 to G.W.).

\section{References}

1 Menasche P: Cardiac cell therapy: lessons from clinical trials. J Mol Cell Cardiol 2011;50:258-265.

2 Heng BC, Haider HK, Sim EK, Cao T, Tong GQ, Ng SC: Reprogramming autologous skeletal myoblasts to express cardiomyogenic function. Challenges and possible approaches. Int J Cardiol 2005;100:355-362.

-3 Heng BC, Haider HK, Sim EK, Cao T, Ng SC: Strategies for directing the differentiation of stem cells into the cardiomyogenic lineage in vitro. Cardiovasc Res 2004;62:34-42.

4 Hilber K: Skeletal myocyte plasticity: basis for improved therapeutic potential? Curr Opin Pharmacol 2008;8:327-332.

-5 Takahashi K, Yamanaka S: Induction of pluripotent stem cells from mouse embryonic and adult fibroblast cultures by defined factors. Cell 2006;126:663-676.

6 Zhang J, Wilson GF, Soerens AG, Koonce CH, Yu J, Palecek SP, Thomson JA, Kamp TJ: Functional cardiomyocytes derived from human induced pluripotent stem cells. Circ Res 2009;104:e30-e41.

7 Sadek H, Hannack B, Choe E, Wang J, Latif S, Garry MG, Garry DJ, Longgood J, Frantz DE, Olson EN, Hsieh J, Schneider JW: Cardiogenic small molecules that enhance myocardial repair by stem cells. Proc Natl Acad Sci U S A 2008;105:6063-6068.

8 Taubenschmid J, Weitzer G: Mechanisms of cardiogenesis in cardiovascular progenitor cells. Int Rev Cell Mol Biol 2012;293:195-267.

-9 Wu X, Ding S, Ding Q, Gray NS, Schultz PG: Small molecules that induce cardiomyogenesis in embryonic stem cells. J Am Chem Soc 2004;126:1590-1591.

10 Weigl LG, Hohenegger M, Kress HG: Dihydropyridine-induced $\mathrm{Ca}^{2+}$ release from ryanodine-sensitive $\mathrm{Ca}^{2+}$ pools in human skeletal muscle cells. J Physiol 2000;525.2:461-469.

11 Caffrey JM, Brown AM, Schneider MD: $\mathrm{Ca}^{2+}$ and $\mathrm{Na}^{+}$currents in developing skeletal myoblasts are expressed in a sequential program: reversible suppression by transforming growth factor beta-1, an inhibitor of the myogenic pathway. J Neurosci 1989;9:3443-3453.

12 Yau WW, Tang MK, Chen E, Yaoyao, Wong IW, Lee HS, and Lee KK: Cardiogenol C can induce Mouse Hair Bulge Progenitor Cells to Transdifferentiate into Cardiomyocyte-like Cells. Proteome Sci 2011;9:3.

$\checkmark 13$ Edwards MK, McBurney MW: The concentration of retinoic acid determines the differentiated cell types formed by a teratocarcinoma cell line. Dev Biol 1983;98:187-191.

14 Bugorsky R, Perriard JC, Vassalli G: N-cadherin is essential for retinoic acid-mediated cardiomyogenic differentiation in mouse embryonic stem cells. Eur J Histochem 2007;51:181-192. 
15 Zebedin E, Sandtner W, Galler S, Szendroedi J, Just H, Todt H, Hilber K: Fiber type conversion alters inactivation of voltage-dependent sodium currents in murine C2C12 skeletal muscle cells. Am J Physiol Cell Physiol 2004;287:C270-C280.

16 Jung D, Shimogawa H, Kwon Y, Mao Q, Sato S, Kamisuki S, Kigoshi H, Uesugi M: Wrenchnolol derivative optimized for gene activation in cells. J Am Chem Soc 2009;131:4774-4782.

17 Deldicque L, Theisen D, Bertrand L, Hespel P, Hue L, Francaux M: Creatine enhances differentiation of myogenic C2C12 cells by activating both p38 and Akt/PKB pathways. Am J Physiol Cell Physiol 2007;293:C1263-C1271.

18 Hoebaus J, Heher P, Gottschamel T, Scheinast M, Auner H, Walder D, Wiedner M, Taubenschmid J, Miksch M, Sauer T, Schultheis M, Kuzmenkin A, Seiser C, Hescheler J, Weitzer G: Embryonic Stem Cells Facilitate the Isolation of Persistent Clonal Cardiovascular Progenitor Cell Lines and Leukemia Inhibitor Factor Maintains Their Self-Renewal and Myocardial Differentiation Potential in vitro. Cells Tissues Organs 2013;197:249-268.

19 Mosmann T: Rapid colorimetric assay for cellular growth and survival: application to proliferation and cytotoxicity assays. J Immunol Methods 1983;65:55-63.

20 Koley M, Mike AK, Heher P, Koenig X, Schön M, Schnürch M, Hilber K, Weitzer G, Mihovilovic MD: VUTMK142: a new cardiomyogenic small molecule promoting the differentiation of pre-cardiac mesoderm into cardiomyocytes. MedChemComm 2013;4:1189-1195.

21 Koley M, Schnürch M, Mihovilovic MD: Selective and Facile Pd-Catalyzed Amination of 2-Fluoro-4-iodopyridine in 4-Position under Microwave Conditions. Synlett 2010;10:1505-1510.

-22 Koley M, Wimmer L, Schnürch M, Mihovilovic MD: Regioselective Synthesis of 2,3-Substituted Pyridines via Orthogonal Cross-Coupling Strategies. Eur J Org Chem 2011;1972-1979.

-23 Zebedin E, Mille M, Speiser M, Zarrabi T, Sandtner W, Latzenhofer B, Todt H, Hilber K: C2C12 skeletal muscle cells adopt cardiac-like sodium current properties in a cardiac cell environment. Am J Physiol Heart Circ Physiol 2007;292:H439-H450.

24 Lee SW, Kang HJ, Lee JY, Youn SW, Won JY, Kim JH, Lee HC, Lee EJ, Oh SI, Oh BH, Park YB, Kim HS: Oscillating pressure treatment upregulates connexin 43 expression in skeletal myoblasts and enhances therapeutic efficacy for myocardial infarction. Cell Transplant 2009;18:1123-1135.

-25 Spadaccio C, Rainer A, Trombetta M, Centola M, Lusini M, Chello M, Covino E, De Marco F, Coccia R, Toyoda Y, Genovese JA: A G-CSF functionalized scaffold for stem cells seeding: a differentiating device for cardiac purposes. J Cell Mol Med 2011;15:1096-1108.

-26 Jasmin, Spray DC, Campos de Carvalho AC, Mendez-Otero R: Chemical induction of cardiac differentiation in p19 embryonal carcinoma stem cells. Stem Cells Dev 2010;19:403-412.

27 Skerjanc IS: Cardiac and skeletal muscle development in P19 embryonal carcinoma cells. Trends Cardiovasc Med 1999;9:139-143.

28 Wang DW, George Jr AL, Bennett PB: Comparison of heterologously expressed human cardiac and skeletal muscle sodium channels. Biophys J 1996;70:238-245.

29 Richmond JE, Featherstone DE, Hartmann HA, Ruben PC: Slow inactivation in human cardiac sodium channels. Biophys J 1998;74:2945-2952.

-30 Zimmer T: Effects of tetrodotoxin on the mammalian cardiovascular system. Mar Drugs 2010;8:741-762.

-31 Haufe V, Chamberland C, Dumaine R: The promiscuous nature of the cardiac sodium current. J Mol Cell Cardiol 2007;42:469-477.

-32 Barton PJ, Robert B, Cohen A, Garner I, Sassoon D, Weydert A, Buckingham ME: Structure and sequence of the myosin alkali light chain gene expressed in adult cardiac atria and fetal striated muscle. J Biol Chem 1988;263:12669-12676.

-33 Saggin L, Gorza L, Ausoni S, Schiaffino S: Cardiac troponin T in developing, regenerating and denervated rat skeletal muscle. Development 1990;110:547-554.

-34 Kallen RG, Sheng ZH, Yang J, Chen LQ, Rogart RB, Barchi RL: Primary structure and expression of a sodium channel characteristic of denervated and immature rat skeletal muscle. Neuron 1990;4:233-242.

-35 Willems E, Bushway PJ, Mercola M: Natural and synthetic regulators of embryonic stem cell cardiogenesis. Pediatr Cardiol 2009;30:635-642.

-36 Ao A, Hao J, Hong CC: Regenerative chemical biology: current challenges and future potential. Chem Biol 2011;18:413-424.

-37 Bettiol E, Clement S, Krause KH, Jaconi ME: Embryonic and adult stem cell-derived cardiomyocytes: lessons from in vitro models. Rev Physiol Biochem Pharmacol 2006;157:1-30.

- 38 Perino MG, Yamanaka S, Li J, Wobus AM, Boheler KR: Cardiomyogenic stem and progenitor cell plasticity and the dissection of cardiopoiesis. J Mol Cell Cardiol 2008;45:475-494.

39 Ruff RL: Cells use the singular properties of different channels to produce unique electrical songs. Biophys J 1998;74:2745-2746. 